\title{
VİDEO KULÜP SÜRECİNE KATILAN ÖĞRETMENLERİN DENEYİMLERİNİ YANSITAN BİR FENOMENOGRAFi் ARAŞTIRMASI
}

\author{
Gülşah Özdemir Baki ${ }^{1}$ \\ ${ }^{1}$ Atatürk Üniversitesi, Oltu Beşeri ve Sosyal Bilimler Fakültesi, Maliye Bölümü \\ gulsah.baki@atauni.edu.tr, http://orcid.org/0000-0002-1497-6528 \\ Gönderme Tarihi: $10.09 .2020 \quad$ Kabul Tarihi: 16.11 .2020
}

Doi: $10.17522 /$ balikesirnef.793164

Özet - Video tabanlı bir mesleki gelişim modeli olan video kulüp, bir grup öğretmenin kendi veya meslektaşlarının video derslerini izleyerek fark ettikleri durumlar hakkında tartışmalar yürüttükleri bir süreçtir. Bu araştırmanın amacı, mesleki vizyonlarını geliştirmek amacıyla video kulübe katılan beş ortaokul matematik öğretmeninin süreç hakkındaki görüşlerini yansıtmaktır. Dolayısıyla bu araştırma fenomenografik bir araştırma yaklaşımı çerçevesinde geliştirilmiştir. Araştırmanın verileri öğretmenlerle yapılan yarı yapılandırılmış görüşmelerden elde edilmiş ve içerik analizine tabi tutulmuştur. Öğretmenlerle yapılan görüşmelerden elde edilen veriler, video kulüp sürecinin öğretmenlerin fark etmelerini, öğrenciyi tanımalarını, duyarlı öğretim uygulamalarını ve öğrenmelerini desteklediğini göstermiştir. Bu anlamda video kulüplerin öğretmenlerin mesleki gelişimlerini olumlu yönde etkilediği söylenebilir. Bu durum video kulüplerin diğer mesleki gelişim programlarına göre daha esnek uygulanabilirliğinin bir göstergesi olarak da düşünülebilir. Ayrıca çalışmada öğretmenlerin kendi ve meslektaşlarının sınıf videolarını analiz etme deneyimlerini yansıtan görüşlerine yer verilerek etkili bir video kulüp tasarımına yönelik önerileri sunulmuştur. Öğretmen önerileri doğrultusunda video kulüp çalışmalarının mesleki gelişim uygulamalarında istenilen etkileri oluşturabilecek şekilde nasıl süreklilik gösterebileceği araştırılabilir. Anahtar kelimeler: Öğretmen mesleki gelişimi, mesleki gelişim modelleri, video kulüp, matematik öğretmeni 


\section{Giriş}

İnsanlık tarihinde eğitimin kurumsallaşmaya başlaması ile birlikte öğretmen her zaman öğretimin önemli bileşenlerinden biri olmuştur. Öğretmenin toplum içindeki rolü ve sahip olması gereken nitelikleri sonraki dönemlerde öğretmenin mesleki yeterlilikleri adı altında tartışılmaya başlanmış ve bu tartışma günümüze kadar gelirken matematik eğitiminde geniş bir yer bulmuştur. Öğretmenlerin mesleki yeterlilikleri, mesleğini etkili bir biçimde yürütebilmesi için sahip olması gereken mesleki bilgi, beceri, tutum ve değerleri içerisinde barındırarak bir bütünlük oluşturmaktadır (Milli Eğitim Bakanlığı [MEB], 2017). Nitekim içinde bulunduğumuz toplumsal yaşamın devamlı bir değişim içerisinde olması, öğretmenlerin mesleki yeterliliklerinin sürekli sorgulanmasını ve geliştirilmesini gerektirmektedir. Bu durum, öğretmenlerin kendilerini geliştirmelerine imkân sağlayan mesleki gelişim süreçlerinin önemini açıkça ortaya koymaktadır. Kaliteli bir mesleki gelişim, eğitimin geliştirilmesi için hemen hemen her modern programın merkezi bir bileșenidir. Bununla ilgili olarak Guskey 'in (2002) öğretmen değişim sürecine yönelik oluşturduğu modelde, öğretmenlerin tutum ve inançlarında önemli bir değişikliğin olması için öncelikle öğrenci öğrenmelerinin iyileştirilmesi söz konusudur. $\mathrm{Bu}$ iyileştirmeler ise, öğretmenlerin duyarlı öğretim uygulamalarını geliştirecek öğrenme araçları ile mümkün olabilir.

Video kullanımı öğretmenlerin mesleki gelişimlerini desteklemek için uluslararası alanda yaygınlaşan bir uygulama şekli olarak karşımıza çıkmaktadır (Christ, Arya \& Chiu, 2017). Özellikle video etiketleme, düzenleme ve paylaşma gibi video teknolojisindeki yeni gelişmeler, videonun öğretmen eğitiminde kullanımını daha da yaygınlaştırmaktadır (Gaudin \& Chaliès, 2015). Etkili bir öğrenme aracı olarak kullanılan video, sınıf uygulamalarının karmaşıklığını gösterebilmekte ve öğrenci düşünmesini görünür hale getirebilmektedir (Barnhart \& van Es, 2015; Santagata \& Yeh, 2013). Bununla birlikte öğretmenlerin dikkat etmedikleri önemli sınıf olaylarını yakalayabilmekte ve istenildiği zaman tekrar izlenme olanağı tanımaktadır (Brophy, 2004). Bu yönüyle videolar, öğretmenlerin kendi veya meslektaşlarının öğretim uygulamalarını gözlemlemelerine de firsat vermektedir (Borko, Jacobs, Eiteljorg \& Pittman, 2008; Seago, 2004; Sherin \& van Es, 2009). Videonun önemli bir öğrenme arac1 olmas1, öğretmen öğrenmesini desteklemek için öğretmen eğitimcileri ve mesleki program geliştiricileri tarafından çeşitli video tabanlı programların kullanılmasına öncülük etmektedir. (örn. Amador, Keehr, Wallin \& Chilton, 2020; Goldsmith \& Seago, 2011; Sherin \& van Es, 2005).

Matematik öğretiminde videonun rolünü araştıran çalışmalar ise, genellikle öğretmenlerin sınıf içi etkileşimlerden ne öğrenmeleri gerektiği ile ilgilenmiştir (Sherin, 2004). 
$\mathrm{Bu}$ yönde, öğretmenlerin sınıf etkileşimlerinin önemli özelliklerini fark etmelerini ve yorumlamalarını sağlamak amacıyla, matematik öğretiminde yaygın kullanılan video kulüp modeli dikkat çekmektedir.

\section{Video Kulüp Modeli}

Video kulüp, bir grup öğretmenin kendi veya meslektaşlarının video derslerini izleyerek fark ettikleri durumlar hakkında yansıtıcı tartışmalar geliştirdikleri bir süreçtir. Son zamanlarda matematik ve fen öğretiminde popülerliğini arttıran video kulüp modeli, öğretmenlerin duyarlı öğretim uygulamalarını desteklemek ve analitik düşüncelerini ortaya çıkarmak amacıyla kullanılan bir öğrenme süreci olarak kabul görmektedir (Luna \& Sherin, 2017; Sherin \& Han, 2004). Bu süreçte, bir grup öğretmen kendi veya meslektaşlarının ders videoları aracılığıyla sınıfta ortaya çıkan önemli etkileşimleri dikkatlice izleyerek, bu etkileşimlerin öğrencilerin öğrenmesini nasıl etkilediğini değerlendirir (Santagata \& Yeh, 2013). Video kulüp modelini diğer mesleki gelişim ortamlarından ayıran önemli bir özelliği ise, bu sürece katılanların sınıfta ne yapacaklarından ziyade, sınıfta gerçekleşen olayları nasıl yorumlayacaklarını ve öğretimlerine nasıl yansıtacaklarını öğrenmeleridir (Sherin, 2004, s.14).

Genellikle bir video kulüp, belirli bir amaç doğrultusunda öğretmen ve araştırmacıların katılımı ile oluşturulur. Video kulüp toplantısında öğretmenler bir veya daha fazla video bölümünü izleyerek, fark ettikleri durumlara ilişkin tartışmalar yürütürler. $\mathrm{Bu}$ sırada araştırmacı, her video kulüp toplantısında kolaylaştırıcı rolünü üstlenerek video dersinin hangi sınıf düzeyinde ve hangi konuyla ilgili olduğunu özetleyerek grubun video dersini izlemesine öncülük eder. Ayrıca kulüp toplantısının amacına göre, öğretmenlerin tartışmalarını yönlendirerek geliştirmelerine yardımcı olur. Örneğin, öğrencilerin matematiksel düşünmelerini fark etmeye yönelik tasarlanan bir video kulüpte, kolaylaştırıcının amacı öğrencilerin matematiksel düşüncelerini fark etme ve yorumlamalarında öğretmenlere yardımcı olmaktır. Bu yönüyle video kulüp, öğretmenlerin sınıf etkileşimlerini anlamlandırmalarına yardımcı olmakta (Star \& Strickland, 2007; van Es \& Sherin, 2008) ve öğrenci düşünmesine odaklanmalarını sağlamaktadır (Jacobs, Lamb \& Philipp, 2010; Sherin \& Han, 2004; Sherin \& van Es, 2009). Aynı zamanda video kulüpler, öğretmenlerin birbirlerinin fikirlerini dinleyerek, anlamaya çalışarak, zıt fikirler ileri sürerek kendi ve meslektaşlarının sınıf uygulamalarına yönelik farklı bakış açıları geliştirmelerine olanak sağlar.

Konu ile ilgili yapılan araştırma sonuçları, video kulüplerin öğretmenlerin kısmi, ayrıntılı olmayan açıklayıcı analizlerden daha odaklı, ayrıntılı ve yorumlayıcı analizlere geçişlerini teşvik ettiğini göstermektedir (örn. Sherin \& Han, 2004; Sherin \& van Es, 2005; van Es \& 
Sherin, 2008). Bu yönde Jilk (2016) çalışmasında, matematik sınıflarının yeniden kültürlenmesini amaçlayan çok boyutlu bir mesleki gelişim ağ modelinin bileşeni olarak video kulübü açıklamıştır (bkz. Şekil 1). Ayrıca çalışmasında öğretmenlerin video kulüp aracılığı ile öğrencilerin matematiksel etkinliklerini görme ve bu etkinlikler hakkında konuşma biçimlerindeki değişimi incelemiştir.

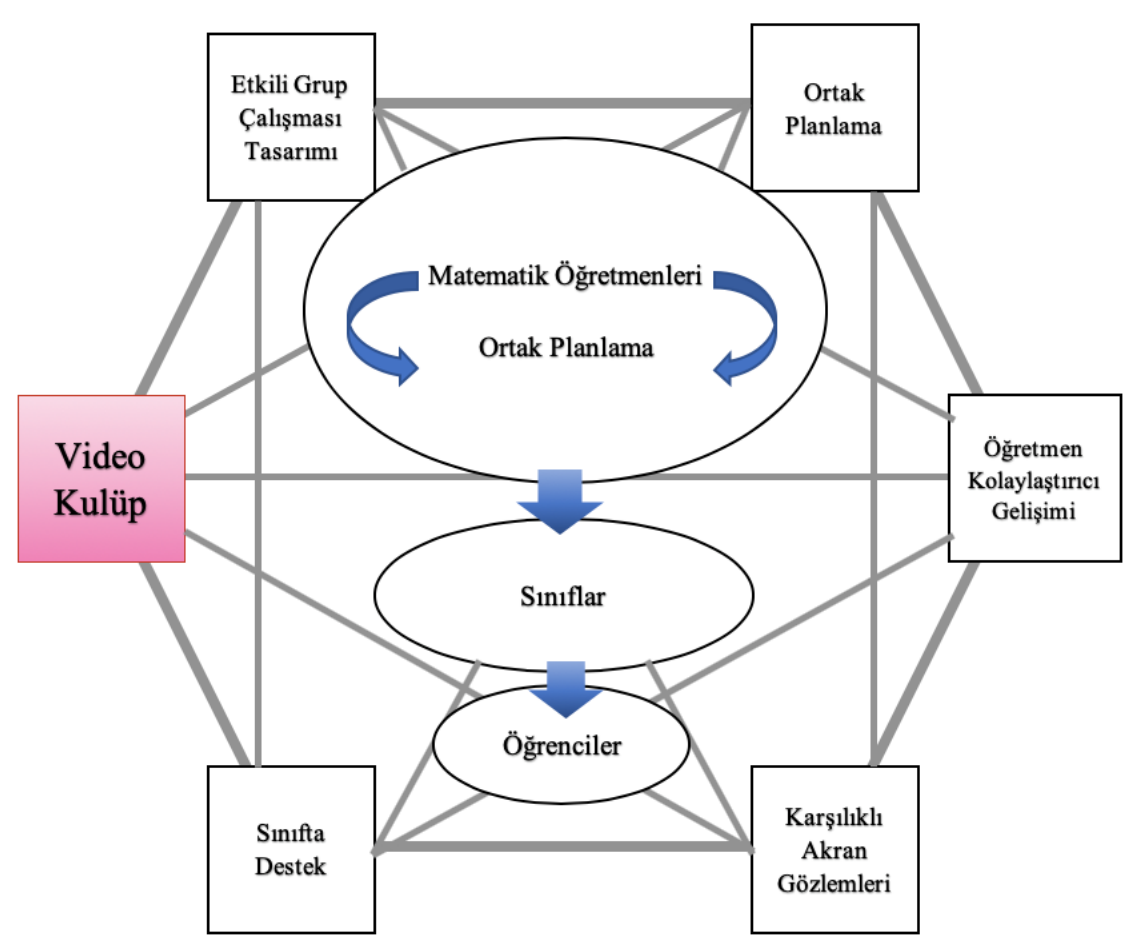

Şekil 1 Mesleki Gelişim Ağ Modeli (Jilk, 2016)

Jilk’e (2016) göre, mesleki gelişim ağ modelinde yer alan diğer öğrenme alanlarının hiçbiri hem program kolaylaştırıcılarına hem de matematik öğretmenlerine aynı sınıf etkinliklerini aynı anda gözlemlemeleri için firsat vermemektedir. Oysa ki video kulüp hem öğretmenlere hem de kolaylaştırıcılara bu imkanı sağlamaktadır. Stürmer, Könings ve Seidel (2013) çalışmalarıyla, video tabanlı mesleki gelişim programlarının geleneksel kurslardan daha etkili olduğunu ortaya koymuşlardır. Yine konu ile ilgili olarak Barnhart ve van Es (2020) çalışmalarında öğretmenlerin video kulüp bağlamında eleştirel bir söylem geliştirip geliştirmediklerini ve nasıl geliştirdiklerini araştırmışlardır. Araştırmanın sonucunda, video kulübe katılan öğretmenlerin öğretme ve öğrenme hakkında daha işbirlikçi, yorumlayıcı ve kanıta dayalı söylemler geliştirdikleri görülmüştür. Diğer yandan Wallin ve Amador (2019) çalışmalarında, öğrenci düşünmesini fark etmeye yönelik tasarlanan bir video kulübe katılan 
öğretmenlerin fark ettikleri içeriğin pedagojik tasarım kapasitelerini nasıl etkilediğini araştırmışlardır. Çalışmaları sonucunda, video kulüp sürecinin öğretmenlerin pedagojik tasarım kapasitelerini ve işbirliği görüşlerini etkilediğini ortaya koymuşlardır. Ayrıca öğretmenlerin öğrenci düşünmelerini fark etme ve kullanma yeteneklerinin geliştiği görülmüştür.

Konu bazında yapılan çalışmalar incelendiğinde, video kulüp sürecinin farklı öğrenme hedeflerini içerecek doğrultuda tasarlandığı görülmektedir. $\mathrm{Bu}$ yönde bazı araştırmalar öğretmenlerin fark ettikleri durumları analiz etmekle ilgilenirken (örn. Star \& Strickland, 2008; van Es, 2011) bazı araştırmalar öğrencilerin matematiksel düşünmelerine yönelik öğretmenlerin anlama ve yorumlama yaklaşımlarıyla ilgilenmiş (örn. Beisiegel, Mitchell \& Hill, 2018; Goldsmith \& Seago, 2011; Jacobs vd., 2010; Luna, Selmer \& Rye, 2018; Sherin \& van Es, 2009; van Es \& Sherin, 2008) ve bazıları ise öğretmenlerin öğretim uygulamalarında meydana gelen değişiklikleri ele almışlardır (örn. Özdemir-Baki \& Kılıçoğlu, 2020; Borko, Koellner \& Jacobs, 2014; Sun \& van Es, 2015; van Es \& Sherin, 2010). Yine ilgili alan yazında, mesleki gelişim modeli olan video kulübün, öğretmenlerin mesleki vizyonlarını ve gelişimlerini desteklemek için verimli bir süreç olduğunu gösteren çalışmalar da bulunmaktadır (Seago, 2004; Seidel, Stürmer, Blomberg, Kobarg \& Schwindt, 2011; Sherin, 2004; Sherin \& van Es, 2005; Sherin \& van Es, 2009; van Es, 2011; van Es, Cashen, Barnhart \& Auger, 2017). Dolayısıyla video kullanarak matematik öğretmenleri ile çalışmayı kolaylaştıran uygulamaların neler olduğunun ortaya konulması öğretmenlerin mesleki gelişimleri için önemlidir (Coles, 2019). Ayrıca video kulüplerin öğretmen ihtiyaçları doğrultusunda uyarlanabilen esnek bir yapıya sahip olması (Borko, Koellner, Jacobs \& Seago, 2011), öğretmen eğitiminde önemli bir rol oynamasını sağlamaktadır. Bu yönüyle kulüp çalışmaları öğretmenlerin duyarlı öğretim uygulamalarını canlandıran bir yöntem olarak kabul görmektedir (Tekkumru-Kisa \& Stein, 2017; Zhang, Lundeberg, Koehler \& Eberhardt, 2011). Bu durum, video kulüp modelinin öğretmenlerin mesleki gelişimi için önemini açıkça ortaya koymaktadır.

Buna karşılık ilgili alan yazında, mesleki vizyonlarını geliştirmek için video kulüplere katılan öğretmenlerin süreç hakkındaki görüşlerini ele alan az sayıda araştırmaya rastlanmıştır. Bununla ilgili olarak van Es ve Sherin (2010) çalışmalarında, video kulübe katılan öğretmenlerin öğretim uygulamalarına yönelik görüşlerini incelemişlerdir. Benzer şekilde Özdemir-Baki ve Kılıçoğlu (2020) video kulübe katılan ortaokul öğretmenlerinin sınıf uygulamalarında meydana gelen değişiklikleri incelemişlerdir. Çalışmalarında aynı zamanda öğretmenlerin uygulamalarıyla ilgili görüşlerine de yer vermişlerdir. Bu çalışmada ise video kulüp sürecinin farklı boyutları (mesleki gelişime katkısı, meslektaş sınıf videolarını analiz 
etme, kendi sınıf videolarını analiz etme, video kulüp toplantıları, etkili bir video kulüp tasarımı) hakkında öğretmenlerin görüşleri alınarak çalışmanın kapsamı genişletilmiştir. Bir mesleki gelişim sürecinin niteliğinin artırılması, bizzat sürecin içerisinde yer alan öğretmenlerin görüş ve düşünceleriyle mümkün olabilir. Çünkü süreç hakkında en iyi değerlendirmeleri yaparak alternatif çözümler önerebilecek pozisyonda olan öğretmenlerdir. $\mathrm{Bu}$ açıdan bakıldığında, video kulübe katılan öğretmenlerin süreç hakkında en gerçekçi değerlendirmeleri yapabilecekleri ve uygulanabilir olması için çözüm odaklı öneriler paylaşabilecekleri düşünülmektedir. Dahası video kulüplerin öğretmenlerin mesleki gelişiminde istenen etkileri yapabilecek şekilde sürdürülebilir olmasında öğretmenlerin görüş ve düşünceleri oldukça önemlidir. Bu bakış açısı altında çalışmanın problemi şöyledir:

Video kulüp mesleki gelişim sürecine dahil olan ortaokul matematik öğretmenlerinin süreç hakkındaki görüşleri nelerdir?

\section{Yöntem}

\section{Araştırmanın Deseni}

$\mathrm{Bu}$ çalışma fenomenografi araştırma yaklaşımı çerçevesinde geliştirilmiştir. Fenomenografi, düşünme ve öğrenme ile ilgili belirli soruları cevaplamak için tasarlanan bir araştırma yaklaşımı (Marton, 1986) olup nitel araştırma deseni içerisinde yer alır (Trigwell, 2006). Fenomenografik araştırmanın amacı, bireylerin bir fenomenin belirli bir yönünü ilişkin deneyimleri anlamada veya kavramsallaştırmada ortaya koydukları farklı yolları araştırmaktır (Marton, 1986). Başka bir ifadeyle, fenomeni bireylerin algıladı̆̆ şekliyle tarif etmektir. Dolayısıyla bu araştırma yönteminin odak noktası bireylerin öznel deneyimleridir. Eğitim çalışmalarında ise fenomenografi bireyin deneyimlerinin doğasını yorumlama ile öğrenme ve öğretmeyi geliştirme amaçları doğrultusunda kullanılmaktadır (Akerlind, 2002). Bu çalışma, video kulüp sürecine katılan bir grup ortaokul matematik öğretmeninin sürece ilişkin deneyimlerini yansıtmaya yönelik tasarlandığı için bir fenomenografi araştırmasıdır.

\section{Katılımcilar}

$\mathrm{Bu}$ çalışma, Türkiye'nin doğu bölgesinde bulunan bir devlet ortaokulunda görev yapmakta olan beş kadın matematik öğretmeni ile yürütülmüştür. Fenomenografik araştırmalarda, katılımcıların araştırılan fenomenle ilgili yaşanmış deneyimlere sahip olmaları gerekir. Bu nedenle çalışma grubunu, 2018-2019 eğitim-öğretim yılının bahar döneminde araştırmacının yürüttüğü video kulüp sürecine dahil olan öğretmenler oluşturmaktadır. 
Katılımc1 öğretmenlerin mesleki deneyimleri altı ile on beş yıl arasında değişiklik göstermektedir. Araştırmanın etiği gereği, öğretmenlerin gerçek isimleri yerine Ö1, Ö2, Ö3, Ö4 ve Ö5 şeklinde kod isimler kullanılmıştır.

\section{Video Kulüp Süreci}

Katılımcı öğretmenler, araştırmacı ve bir matematik eğitimcisinin katılımı ile bir video kulüp oluşturulmuştur. Araştırmacı tarafından her hafta bir öğretmenin dersi video kayıt altına alınarak video kulüp toplantısında gösterilmiştir. Video kulüp katılımcıları, haftada bir kez öğretmenlerin görev yaptıkları okulda bir araya gelmiştir. Öğretmenler, döngüsel bir şekilde kayıt altına alınan video derslerini dikkatli bir şekilde izleyerek fark ettikleri durumlar hakkında tartışmalar geliştirmişlerdir. Aynı zamanda öğretmenler video dersini izlerken kendi ve meslektaşlarının öğretim uygulamalarına yönelik değerlendirmeler de yapmışlardır. Dolayısıyla video kulüp toplantıları yaklaşık bir saat sürmüştür. Araştırmacı video kulüp toplantılarında kolaylaştırıcı rolünde olup öğretmenlerin fark ettikleri durumlar hakkında detaylı bilgi edinmek için sorular yöneltmiş ve onların öğrenci düşünmeleri üzerine odaklanmalarını sağlamıştır. On bir hafta süren video kulüp uygulamaları tamamlandıktan yaklaşık bir ay sonra öğretmenlerin süreçle ilgili deneyimlerini yansıtmak amacıyla görüşmeler yapılmıştır.

\section{Veri Toplama}

$\mathrm{Bu}$ araştırmanın verileri, video kulüp sürecine dahil olan öğretmenlerle yapılan yarı yapılandırılmış görüşmelerden elde edilmiştir. Araştırmacı tarafından video kulüp sürecine yönelik öğretmen deneyimlerini yansıtmak amacıyla, yarı yapılandırılmış bir görüşme formu hazırlanmıştır. Bu form beş açık uçlu sorudan oluşmaktadır. İlk soru, video kulüp sürecinin katkılarına yönelik öğretmenlerin görüşlerini belirlemek amacıyla hazırlanmıştır. İkinci ve üçüncü soru öğretmenlerin kendi ve meslektaşlarının videolarını izleyerek değerlendirmelerine yönelik deneyimlerini ortaya koymaktadır. Dördüncü soru, video kulüp tartışma toplantılarına yönelik öğretmen deneyimlerini yansıtmak amacıyla oluşturulmuştur. Son soru ise, daha etkili bir video kulüp sürecinin tasarlanması için öğretmenlerin önerilerini içermektedir. Görüşme soruları hazırlandıktan sonra geçerliği sağlamak amacıyla iki matematik eğitimcisinin görüşleri alınmış ve gerekli düzenlemeler yapılmıştır. Örneğin, birinci soruda "katkıları" ifadesi "mesleki gelişiminize katkıları” olarak değiştirilmiştir. Daha sonra görüşme soruları çalışmaya dahil olmayan iki matematik öğretmeni ile değerlendirilerek soruların anlaşılır olduğu belirlenmiştir. Araştırma verileri toplanırken her bir öğretmen ile yaklaşık 30 dakika süren görüşmeler 
yapılmış ve bu görüşmeler video kamera kullanılarak kayıt altına alınmıştır. Analizler yapılmadan önce görüşmelerden elde edilen veriler bilgisayar ortamında yazıya geçirilerek beş öğretmenin ayrı ayrı ses dökümleri oluşturulmuştur. Yazılı metne dönüştürülen sözel konuşmaların doğruluğunu ve gerçekliğini kontrol etmek için görüşmeye katılan öğretmenlerden kendi ifadelerini teyit etmeleri istenilmiştir.

\section{Veri Analizi}

$\mathrm{Bu}$ çalışmada, öğretmenlerle yapılan yarı yapılandırılmış görüşmelerden elde edilen verilerin analizinde içerik analiz tekniği kullanılmıştır. İçerik analizinin temel amacı, toplanan verilerin kavramsallaştırılması ve ortaya çıkan kavramların düzenlenerek verileri açıklayacak şekilde anlaşılır hale getirilmesidir (Yıldırım \& Şimşek, 2016). Bu amaçla, ilk olarak yarı yapılandırılmış görüşmelerden elde edilen veriler kendi içinde anlamlı hale getirilmeye çalışılmıştır. $\mathrm{Bu}$ aşamada, öncelikle öğretmenlerin ifadelerindeki benzerlikler ve farklılıklar belirlenerek verilerin taslak kodları oluşturulmuştur. $\mathrm{Bu}$ taslak kodları içeren bir liste hazırlanmıştır. Elde edilen veriler araştırmacı tarafindan iki hafta sonra tekrar incelenerek kodlar üzerinde düzenlemeler yapılmıştır. Daha sonra birbirleriyle ilişkili olan kodlar belirli kategoriler altında sınıflandırılmıştır.

Çalışmada öğretmenlerle yüz yüze görüşmeler yapılarak ayrıntılı bilgi toplanmış ve elde edilen verilerin dışa aktarımında zengin betimlemelere yer verilmiştir. Diğer yandan öğretmenlerle yapılan her görüşme yazılı metne dönüştürülmüş ve doğruluğu hakkında öğretmenlerden teyit etmeleri istenmiştir. Son olarak, verilerin analizinde elde edilen kodlama kategorileri, iki matematik eğitimcisi tarafından incelenmiş ve öğretmen cevapları ile tutarlığı kontrol edilmiştir. Matematik eğitimcilerinin önerileri doğrultusunda aynı durumu ifade eden bazı kodlar birleştirilmiştir. Örneğin; "öğrenci seviyesine uygun etkinlikler belirleme” ve "öğrenci seviyesine inme" kodları birleştirilerek "öğrenci seviyesini dikkate alma" kodu oluşturulmuştur. Ayrıca öğretmen önerileri kendi içinde sınıflandırılarak üç kategori elde edilmiştir.

\section{Bulgular ve Yorumlar}

Katılımcı öğretmenlerle video kulüp mesleki gelişim sürecine yönelik yapılan görüşmelerden elde edilen veriler analiz edilerek kategori ve kodlar oluşturulmuştur. Her bir soru için oluşturulan kodlama kategorileri tablolar halinde düzenlenerek sunulmuştur. Öğretmenlerin görüşme sırasında, "Video kulüp sürecinin mesleki gelişiminize katkılarının 
neler olduğunu düşünüyorsunuz? sorusuna verdikleri yanıtlara ait analizler Tablo 1'de gösterilmiştir.

\begin{tabular}{|c|c|c|}
\hline Kategoriler & Kodlar & Öğretmenler \\
\hline \multirow{4}{*}{ Fark etme } & Öğrenci fikirlerine odaklanma & Ö1, Ö2, Ö3, Ö4, Ö5 \\
\hline & Öğrencinin matematiksel fikirlerini yorumlama & Ö1, Ö2, Ö4, Ö5 \\
\hline & Sınıf etkileşimlerine dikkat etme & Ö1, Ö2, Ö3, Ö4 \\
\hline & Sınıf etkileşimlerini anlamlandırma & Ö1, Ö5 \\
\hline \multirow{5}{*}{ Öğrenciyi tanıma } & Kavram yanılgılarını belirleme & Ö1, Ö2, Ö3, Ö5 \\
\hline & Öğrencinin ön bilgisini kontrol etme & Ö1, Ö2, Ö4 \\
\hline & Öğrenme güçlüklerini tahmin etme & Ö1, Ö2, Ö3, Ö4 \\
\hline & Öğrenci sorularını tahmin etme & Ö2, Ö4, Ö5 \\
\hline & Öğrenci cevaplarını tahmin etme & Ö1 \\
\hline \multirow{14}{*}{$\begin{array}{l}\text { Duyarlı öğretim } \\
\text { uygulamaları }\end{array}$} & Farklı öğretim yöntemleri kullanma & Ö1, Ö2, Ö4, Ö5 \\
\hline & Öğrenci fikirlerini önemseme & Ö1, Ö2, Ö4 \\
\hline & Öğrenci fikirlerini açığa çıkarma & Ö4, Ö5 \\
\hline & Öğrencinin katılımını sağlama & Ö2, Ö4, Ö5 \\
\hline & Öğrencinin anladığından emin olma & Ö4 \\
\hline & Öğretmen dönütleri & Ö1, Ö2, Ö4, Ö5 \\
\hline & Norm oluşturma & Ö1 \\
\hline & Öğrenci seviyesine dikkat etme & Ö2, Ö3, Ö4, Ö5 \\
\hline & Öğrenciye karşı yaklaşım & Ö1, Ö3, Ö4, Ö5 \\
\hline & Öğrenci fikirlerini sorgulama & Ö1, Ö2, Ö4, Ö5 \\
\hline & Materyal seçimi & Ö1, Ö4, Ö5 \\
\hline & Zaman tanıma & Ö1, Ö4 \\
\hline & Farkl1 çözümler için öğrenciyi destekleme & Ö1, Ö4 \\
\hline & Öğrencinin hata yapmasına firsat verme & Ö2, Ö4 \\
\hline \multirow{3}{*}{$\begin{array}{l}\text { Öğretmenin } \\
\text { öğrenmesi }\end{array}$} & Sonuç yerine sebeplere odaklanmayı öğrenme & Ö2 \\
\hline & Öğretirken öğrenme & Ö4 \\
\hline & Sorgulamayı öğrenme & Ö2, Ö5 \\
\hline
\end{tabular}


Kavram yanılgısına sebep olan söylemleri Ö1, Ö2, Ö3 öğrenme

Tablo 1 Öğretmenlerin Video Kulüp Mesleki Gelişim Deneyimlerini Yansıtan Görüşleri

Tablo 1'de görüldüğü gibi, video kulüp sürecinin öğretmenlerin mesleki gelişimlerine katkıları öğretmenlerin verdikleri yanıtlar dört kategori altında toplanmıştır. Fark etme kategorisi, öğretmenlerin odaklandıkları ve anlamaya çalıştıkları durumları içeren dört kodlamadan oluşmaktadır. Öğretmenlerin tümü video kulüp sürecinin öğrenci fikirlerine odaklanmalarında etkili olduğunu belirtmiştir. Bununla ilgili olarak, Ö3 görüşlerini şöyle ifade etmiştir: “Öncelikle ögrencilerin fikirlerine dikkat etmeye başladım. Neden böyle düşündüğünü anlamaya çalıştım." Ö1 ise “Öğrencilerin aslında farklı fikirlerinin olduğunu ama bunu net ifade edemediklerini gördüm.” açıklamasıyla öğrenci fikirlerine odaklandığını belirtmiştir. Ayrıca öğretmenler öğrencilerin fikirlerine odaklanmakla birlikte bu fikirleri anlamaya ve yorumlamaya çalıştıklarını belirten görüşler sunmuşlardır. Örneğin, Ö2 bununla ilgili düşüncelerini “Öğrencilerin doğru cevaplarının altında bile yanlış düşüncelerinin olduğunu fark ederken, bazen de yanlış cevapların altında farklı düşüncelerin veya bakış açılarının olduğunu fark ettim.” şeklinde açıklamıştır. Ö5, öğrenci düşünmesini anlamaya yönelik görüşlerini “Öğrencilerin özellikle geometri konularında nasıl düşündüklerini anlamaya çalıştım. Mesela, bazı öğrencilerin geometrik şekilleri sadece standart çizimleriyle hafizalarına kaydettiklerini fark ettim." ifadeleriyle belirtmiştir. Ö4 ise video kulüplerin sınıftaki birçok olayı anlama ve yorumlama becerisini geliştirdiğini belirterek sınıf etkileşimlerine yönelik fark ettiği durumlardan bahsetmiştir.

Öğrenciyi tanıma kategorisi, öğretmenlerin öğrenciyi daha yakından tanımak için yaptıkları faaliyetleri kapsamaktadır. Bu kategori altında, çoğu öğretmen öğrencinin öğrenme güçlüklerini ve kavram yanılgılarını belirlemeyle ilgili görüşlerini dile getirmiştir. Öğretmenler video kulüplerin öğrencilerin kavram yanılgılarını belirlemede etkili bir yol olduğu görüşündedir. Bu bağlamda, Ö5 video kulüp sürecinde öğrencilerin kavram yanılgılarını tahmin etmeye başladığını belirtirken, Ö2 ise videoları izlerken öğrenci açısından hangi kavram yanılgılarının ortaya çıkabileceğini fark ettiğinden bahsetmiştir. Bununla birlikte Ö2 öğrencinin ön bilgisini kontrol etmeye yönelik görüşlerini “ Ö̆̆rencilerin ön bilgilerinin önemli olduğunu ve her dersin başında bunun kontrol etmemiz gerektiğini düşünüyorum. Böylece kavram yanılgılarını belirlememiz daha kolay olabilir." şeklinde ifade etmiştir. Öğretmenlerin çoğu sınıf videolarını analiz ederken öğrencilerin öğrenme güçlüklerini tahmin etmeye başladıklarını belirtmişlerdir. Örneğin, Ö3 “Şöyle ki artık ögrencilerin nerede ve nasıl hatalar yapabilirler 
hangi kavramlarda takllabilirler hususunda öngörümün geliştiğini düşünüyorum." açıklamalarını yapmıştır. Ö4 ise öğrencilerin geometri konularında daha fazla zorlandıklarını ve bu nedenle ezberleme yolunu tercih ettiklerinden bahsetmiştir. Öğretmenlerden üçü (Ö2, Ö4, Ö5) video kulüp sürecinin öğrenci sorularını tahmin etme becerilerini geliştirdiğini belirtirken buna karşı1ık Ö1 öğrenci cevaplarını tahmin etme becerisini geliştirdiğini ifade etmiştir. Bu duruma yönelik Ö1 görüşlerini “Videoyu izlerken ögrretmenin sorusu karşısında öğrencinin ne cevap verdiğini izlemeden tahmin etmeye başladım." şeklinde belirtmiştir. Öğretmenlerin görüşlerinden video kulüp sürecinde öğrencilerin ön bilgilerini, kavram yanılgılarını ve öğrenme güçlüklerini belirlemeye çalışarak öğrenciyi daha yakından tanımaya çalıştıkları anlaşılmaktadır.

Video kulübüne katılan öğretmenlerin sınıf uygulamalarına yönelik görüşlerinin oldukça detaylı olması dikkate değer bir bulgudur. Öğretmenlerin yanıtları, öğretim uygulamalarında daha çok öğrenciyi merkeze alan yaklaşımlar benimsediklerini göstermektedir. Dolayısıyla öğretmenlerin bu yaklaşımları duyarlı öğretim uygulamaları kategorisi altında toplanmıştır. Bu kategori kapsamında öğretmenler genel olarak farklı yöntemler kullanmaya başladıklarını, öğrenci fikirlerini daha fazla önemsediklerini, öğrencilerin fikirlerini açığa çıkarmaya çalıştıklarını, bunun için öğrenci fikirlerini sorguladıklarını, öğrencilerin derse katılımını sağlamak için etkinlikler kullandıklarını, bu etkinliklerin seçiminde öğrenci seviyesini göz önüne aldıklarını ve uygun materyalleri seçmeye çalıştıklarını ifade etmişlerdir. Bununla ilgili olarak Ö5 görüşlerini şöyle açıklamıştır: "Daha üst seviyede sorularla başladı̆̆ımı diğer ögretmenlerin ise daha basit sorular çözdüklerini gördüm. İlk örneklerimin bile zor olduğunu fark ettim... daha basit örnekler vererek başlyyorum.” Ö4 ise "Sınıfa giderken hangi materyali kullanmam gerektiğini düşündüğ̈̈mü fark ettim. Öğretmen arkadaşlarıma hangi materyallerden faydalandıklarını soruyorum..." ifadeleriyle materyal seçimine verdiği önemi belirtmiştir. Farklı yöntemler kullanmaya başladığını belirten Ö1, öğretmenlerin sınıf videolarını değerlendirirken farklı yöntemlere odaklandığını ve uygun gördüğü yöntemleri kendi derslerinde kullanmaya başladığını dile getirmiştir. Bu anlamda Ö4, öğrencilerin hayal güçlerini kullanmalarını, kendilerini o sorunun içinde hissetmelerini ve nasıl bir çıkış yolu bulabileceklerini düşünmelerini sağlayacak yöntemler kullanmaya başladığından söz etmiş ve görüşmenin devamında “Geometri konularına yönelik hazırlanan programları kullanmanın ne kadar etkili olduğunu gördüm ve bu programı kendi derslerimde kullanmaya başladım. Öğrencilerim istedikleri gibi açıları değiştirerek farklı üçgenler oluşturdu ..." açıklamalarını yapmıştır. Buna ek olarak, Ö5 öğrenci fikirlerini açığa çıkarmaya daha fazla önem verdiğinden bahsetmiş ve bunu sağlamak için tartışma ortamları oluşturduğunu dile getirmiştir. Böylece 
hangi öğrencinin nasıl bir fikri olduğunu anlamanın daha kolay olduğunu belirtmiştir. Öğrenciye yönelik yaklaşımının değiştiğinden bahseden Ö3 ise görüşlerini şöyle açıklamıştır: "Sınıf içi uygulamalarımda konuyu veya çözdüğümüz herhangi bir soruyu öğrencilerle tartışırken, ögrencileri kendi kafamdaki doğrulara yönlendirdiğimi fark ettim.” Bununla ilgili olarak Ö5 ise, sabırsız davrandığını ve öğrencilere fazla müdahalede bulunduğunu belirtmiştir. $\mathrm{Bu}$ durumun öğrencinin düşünmesine fursat vermediği gibi aynı zamanda öğretmenin de öğrenciyi tanımasına engel olduğunu ifade etmiştir. Öğrencilerin düşünceleri yeterince ifade edemediklerini belirten Ö1, bu durumu şöyle açıklamıştır: “Özellikle öğrencilerin matematiksel ifadeleri kullanmakta çok zorlandıklarını gördüm. Bu da öğrencinin anlatmak istediklerinin anlaşılmamasına neden olabiliyor.” Benzer şekilde Ö4, öğrencilerinin fikirlerini önemsediğini ve yanlış cevaplar bile verseler onları dinleyerek düşünme şekillerini anlamaya çalıştığından bahsetmiştir. Buna karşılık Ö2, öğrencilerin doğru olup olmadığını sorgulamadan her fikrini kabul ettiğini ve bunun önüne geçebilmek için öğrenci fikirlerini sorgulamaya başladığını belirtmiştir. Bu duruma farklı bir bakış açısıyla yaklaşan Ö1 “Öğretmenlerin öğrenci fikirlerini sorgulamaya önem vermesi, öğrencinin matematiksel anlayışlarını geliştiriyor aslında. Çünkü ögrenci bir süre sonra şunu biliyor ki bu cevabı söylersem öğretmen aynı zamanda nasıl yaptığımı da soracak neden böyle düşündüğümü de soracak.” ifadeleriyle aslında sinıfta oluşturulan örtük kurallar olarak nitelendirilen sosyal normlardan bahsetmiştir. Öte yandan herhangi bir problemin çözümünü öğrencinin anlayıp anlamadığından emin olmak isteyen Ö4, sınıf uygulamalarında alternatif problemlere yer verdiğinden söz etmiştir. Ayrıca öğrencilerin problem çözümlerinde farklı çözüm yolları geliştirmelerini desteklediğini belirterek öğrencilere düşünmeleri için zaman verdiğini dile getirmiştir. Benzer olarak, Ö1 öğrencinin ne düşündüğünü öğrenmeye çalıştığını belirterek görüşmenin devamında fikirlerini şöyle ifade etmiştir: “Öğrencilerin tek bir çözüm yoluna bağlı kalmamalarını istiyorum. Bunun için de farklı çözüm yolları denemelerine ve kontrol etmeleri için yeni stratejiler geliştirmelerine firsat veriyorum."

Yapılan görüşmelerde, öğretmenlerin video kulüp sürecinde fark ederek benimsedikleri yaklaşımlardan bahsettikleri görülmüştür. Bunlar sonuç yerine sebebe odaklanma, öğretirken öğrenme, sorgulamayı öğrenme ve kavram yanılgısına sebep olan söylemleri öğrenme olarak belirlenmiştir. Öğretmenlerin bu yaklaşımları öğretmenin öğrenmesi kategorisi altında toplanmıştır. Öğretmenlerin çoğu, videoları değerlendirirken kavram yanılgısına sebep olabilecek bazı söylemleri fark ettiklerini ifade etmişlerdir. Bununla ilgili olarak Ö3 görüşlerini “Öğrencilerimle olan bilgi alışverişimde bazı küçük noktalara daha fazla dikkat etmem 
gerektiğini ve öğrenci gözünden bu küçük noktanın aslında yanlış öğrenmelere sebep olabileceğini öğrendim, bu konuda daha dikkatli davranmama vesile oldu." şeklinde belirtmiştir. Buna karşılık Ö1 “...kullandığımız ifadeleri öğrenciler genelliyor bu da kavram yanılgılarına sebep oluyor." görüşünü dile getirerek kavram yanılgısının farklı bir sebebine odaklanmıştır. Bunun dışında video kulüp çalışmalarında sonuca değil sebeplere odaklanmayı öğrendiğini ifade eden Ö2, bu durumu öğrencilerin matematiksel düşünmesiyle ilişkilendirmiştir. Bununla ilgili görüşlerini “...̈̈ğrencilerin doğru ve yanlış cevaplarını sorgulamayı öğrendim. Sadece doğru sonuca odaklanmamam gerektiğini öğrencilerin yanıtlarını sorgulayarak neden bu şekilde düşündüklerini anlamayı öğrendim." ifadeleriyle dile getirmiştir. Ö4 ise bir öğrencisinin çözüm stratejisini anlamaya çalıştı̆ğ bir durumda kendisini öğrenen konumda gördüğünü dile getirerek bununla ilgili görüşlerini “Öğrencimin çözüm yolunu anlamak için biraz düşündüm. O an öğrencinin çözüm yolundan emin olamadım. Sonra ders notlarıma bakarak kendi çözümüm ile karşılaştırdım ... ” ifadeleriyle belirtmiştir.

Öğretmenlerin video kulüp sürecinde kendi sınıflarına ait video derslerini izleyerek analiz etme deneyimlerini yansıtan görüşleri Tablo 2'de görüldüğü gibi iki kategori altında sınıflandırılmıştır. Öğretmenler kendi derslerini izleyerek analiz etmelerinin avantajlarını öğrencilerle kurdukları iletişimlerini görme, gözlemci olarak derslerini değerlendirme, öz eleştiri yapma, sınıfları farklı açılardan görme ve dikkate almadıkları durumları önemseme olarak ifade etmişlerdir.

Tablo 2 Öğretmenlerin Kendi Sınıf Videolarını Analiz Etme Deneyimlerini Yansıtan Görüşleri

\begin{tabular}{lll}
\hline Kategoriler & \multicolumn{1}{c}{ Kodlar } & \multicolumn{1}{c}{ Öğretmenler } \\
\hline \multirow{4}{*}{ Avantajları } & Sinıfta öğrencileriyle kurdukları iletişimi görme & Ö1 \\
& Gözlemci olarak öz değerlendirme yapma & Ö1, Ö2, Ö3, Ö4, Ö5 \\
& Öğretim uygulamalarına yönelik öz eleştiri yapma & Ö1, Ö3, Ö4, Ö5 \\
& Sinıfları farklı aç1lardan görme & Ö2 \\
& Dikkate alınmayan durumları önemseme & Ö1, Ö4, Ö5 \\
\hline Dezavantajlar1 & Yansıtıc1 olmaktan kaçınma & Ö2, Ö3 \\
\hline
\end{tabular}

Tablo 2 incelendiğinde, öğretmenlerin tamamı kendi video derslerini analiz etme deneyimlerinin, gözlemci olarak derslerini değerlendirmelerine imkan sağladığını belirtmiştir. Bununla ilgili olarak, Ö1 "kendi derslerimi dışarıdan bir gözlemci gibi dĕgerlendirmeye çalıştım.” ifadesini dile getirmiştir. Ö4 ise “...burada iyiymişim dediğim durumlar da oldu ne yapmışım böyle dediğim durumlarda oldu. Aynayı kendine tutmak gibi..." açıklamalarıyla uygulamalarını değerlendirmiştir. Kendi video derslerini izlemenin değişik bir duygu olduğunu belirterek görüşlerini açıklayan Ö5 ise, öğretim uygulamalarını gözlemleyerek eksik olan 
yönlerini görmeye çalıştığından bahsetmiştir. Bu bağlamda, öğrenciye yeterli zaman tanımayıp çok sabırsız davrandığını dile getirerek öğretim uygulamalarına yönelik öz eleştiri yapmıştır. Bununla ilgili olarak Ö3 ise uygulamalarına yönelik öz eleştirilerini şöyle ifade etmiştir: “Öğrencileri bazen çok etkilediğimi gördüm. Aslında bir soruyu tartışırken düşünmeleri için firsat verdim, farkl fikirleri dinledim ama şunu gördüm onları kafamdaki doğruya göre ikna etmeye çalıştığımı...” Öğretmenlerin çoğu, sınıfta dikkate almadıkları bazı durumları video analizleri sayesinde önemsemeye başladıklarını belirtmişlerdir. Örneğin, Ö1 bununla ilgili olarak görüşlerini şöyle dile getirmiş̧tir: "Sınıfta dikkate almadığım ya da gözümden kaçırdı̆̆ım bazı şeylerin önemli olduğunu gördüm... Tahtada çözmesine rağmen o an sıradan bir çözüm olarak değerlendirmişim. Ama video analizi sırasında öğrencimin üst düzey bir çözüm yaptı̆̆ını fark ettim.” Kendi sınıf videolarını izlemenin çok keyifli olduğunu dile getiren Ö2, video analizleri sayesinde sınıfa sadece bir yönüyle değil birden fazla yönüyle baktığını belirtmiştir. Bu yönde Ö1 “Videoyu izlerken sadece kendi davranışlarımı görmüyorum, aynı zamanda her bir ögrrencimin ne yaptı̆̆ını, nasıl düşündüğünü, nasıl öğrendiğini de görüyorum...” ifadeleriyle sınıfı birden çok açıdan gözlemleyerek değerlendirmiştir. Öte yandan, iki öğretmen kendi sınıf videolarını izleyerek analiz etme deneyimlerine yönelik olumsuz bir görüş belirtmiştir. Öğretmenlerin olumsuz olarak değerlendirdikleri, kendi sınıf uygulamalarına yönelik gerçekleri yansıtıcı olmaktan kaçınma durumlarıdır. Bu bakış açısı altında Ö2 düşüncelerini “kendi öğretim uygulamalarımızı gözlemci gibi değerlendirdiğimizi düşünsek bile çok objektif olduğunu düşünmüyorum. Çünkü kendi eksik yönlerimiz hakkında konuşmaktan kaçınıyoruz..." şeklinde dile getirmiştir.

Öğretmenlerin video kulüp sürecinde meslektaşlarının sınıf videolarını izleyerek analiz etme deneyimlerini yansıtan görüşleri Tablo 3 'te görüldüğü gibi video analizlerinin kazanımları ve olumsuz yönleri olmak üzere iki kategori altında sınıflandırılmıştır.

Tablo 3 Öğretmenlerin Meslektaşlarının Sınıf Videolarını Analiz Etme Deneyimlerini Yansitan Görüşleri

\begin{tabular}{lll}
\hline Kategoriler & \multicolumn{1}{c}{ Kodlar } & \multicolumn{1}{c}{ Öğretmenler } \\
\hline & Farklı öğretim uygulamaların1 gözlemleme & Ö1, Ö2, Ö3, Ö4, Ö5 \\
& ve değerlendirme & \\
& Ç1karımda bulunma & Ö2, Ö3, Ö4, Ö5 \\
& Eleştirel bir bak1ş geliştirme & Ö2, Ö3, Ö4 \\
Kazanımları & Öğretmen ve öğrenci etkileşimlerine dikkat & Ö4 \\
& etme & \\
& $\begin{array}{l}\text { Farklı konular hakkında öğrenci fikirlerini } \\
\text { inceleme }\end{array}$ & Ö1, Ö2, Ö4 \\
\end{tabular}

Necatibey Eğitim Fakültesi Elektronik Fen ve Matematik Eğitimi Dergisi 


\begin{tabular}{lll}
\hline & Öğrenci seviyeleri hakkında bilgi sahibi & Ö2, Ö4 \\
& olmama & \\
Olumsuzluklar1 & Öğrenci ifadelerinin anlaş1lmadığ1 durumlar & Ö1, Ö2 \\
& Sınıf ortamında gözlem olanağının olmamas1 & Ö2 \\
& Öğrencileri tanımama & Ö2, Ö5 \\
\hline
\end{tabular}

Öğretmenlerin tamamı, meslektaşlarının sınıf videolarını izleyerek analiz etmelerinin farklı öğretmenlerin uygulamalarını gözlemlemelerine olanak verdiğinden bahsetmiştir. $\mathrm{Bu}$ durum ile ilgili olarak, Ö4 "Öğretmenlerin sınıf videolarını izlememiz öğrencilerle birlikte ögretmenlerin de nasıl davrandıklarını, hangi yöntemleri kullandıklarını görmemiz açısından iyi oldu. " şeklinde fikirlerini belirtmiş ve görüşmenin devamında bunu bir örnekle açıklamıştır: “Mesela bir öğretmenin sınıfinda ögrrenciler çok rahat davranıyordu. Bir grup materyal ellerinde soruyu çözmeye çalışıyorken diğer bir grup tahtada çözmeye uğraşıyordu bazıları da yerinde bireysel çözmeye çalışıyordu. Gürültü vardı ama öğretmen buna alışmıştı sanırım önemsemedi. Önemli olan ögrrencilerin kendilerinin sonuca ulaşmasıydı... Çok beğendim bir ders oldu ve izlerken ben de yapabilir miyim diye düşündüm?” Ö4’ün açılamalarından anlaşılacağı gibi, öğretmenin öğretim uygulamalarını gözlemlemekle birlikte değerlendirmeler yapmakta ve hatta çıkarımda bulunmaktadır. Benzer olarak Ö1 öğretmenlerin kullandıkları yöntemleri gözlemlediğini belirterek beğendiği yöntemleri derslerinde kullanmaya başladığını ifade etmiştir. Ö2 ise “...kendi anlatım yöntemlerim dlşııda farklı yöntemleri gözlemlememi sağlarken, karşılaştırma yapmamı da sağladı. İzlerken öğrendiğim yöntemler de oldu düşündügüum de oldu bu yöntem daha uygun olmuş diye..." şeklinde belirttiği görüşleriyle kendi uygulamalarını diğer öğretmenlerin uygulamalarıyla karşılaştırarak çıkarımda bulunmuştur. Video kulüplerin meslektaşlarının sınıflarını gözlemleme olanağı sağladığından bahseden Ö3, görüşlerini “...videoları izlemek faydalı oldu benim için. Çünkü her ayrıntıda kendime katacak bir doğru buldum, gözlemlerimden ve analizlerimden çıkardiğım sonuçların faydalı olduğunu düşünüyorum" ifadeleriyle dile getirmiştir. Öğretmenlerin çoğu, meslektaşlarının video derslerini analiz etmeleri sayesinde, öğretim uygulamalarına yönelik eleştirel bir bakış geliştirdiklerini belirtmiştir. Örneğin, Ö5 “Farklı ögretmenlerin uygulamalarını izlerken mantıksal bir sorgulama yapmaya başladım. Karşılaştırmalar yaptım hem kendi uygulamalarımla hem de diğerleriyle ... Burada farklı bir yaklaşım kullanması gerekirdi dediğim zamanlar da oldu." görüşlerini belirterek uygulamalara yönelik eleştirel bir bakış geliştirdiğinden bahsetmiştir. Bunun yanı sıra diğer öğretmenlerden farklı bir görüş dile getiren Ö4, videoları izlerken öğretmen ve öğrenciler arasındaki etkileşimlere dikkat ettiğini belirtmiştir. Ayrıca öğretmenlerin farklı konularda uygulamalarını gözlemleyerek öğrencilerin 
fikirlerini anlamaya çalıştı̆ğndan bahsetmiş ve bu doğrultuda görüşlerini şöyle açıklamıştır: “Öğrencilerin bazı konularda nasıl düşündüklerini anlamak gerçekten zor. Fikirlerini ifade etmekte zorlanıyor çoğu. Videolart izlerken de özellikle ögrencilerin nerede ve nasıl cevaplar verdiklerini anlamaya çalıştım. Ama bunu daha iyi anlamak için öğrenciyi yakından tanımam gerektiğini fark ettim.” Diğer yandan öğretmenler meslektaşlarının ders videolarını analiz etmelerini zorlaştıran dört durumdan bahsetmişlerdir. Öğretmenlerin çoğu, izledikleri videolarda öğrencilerin ön öğrenmeleri hakkında yeterli bilgiye sahip olmadıkları için analiz etme konusunda zorluk yaşadıklarını belirtmiştir. Örneğin, bu durum ile ilgili olarak Ö2 görüşlerini şöyle ifade etmiştir: "En büyük sıkıntı analiz yaparken ögrencilerin ön bilgilerinin yeterli olup olmadı̆̆ını bilmememiz oldu." Ö2'ye göre; hangi öğrencinin hangi seviyede olduğunun bilinmemesi de videoları analiz ederken yaşadıkları olumsuzluklardan biridir. Ayrıca bazı videolarda öğrencilerin ifadelerinin tam olarak anlaşılmadığını belirtmiş ve derslere katılarak gözlem yapmak yerine videoyu izleyerek değerlendirmeler yapmalarının zor olduğunu ifade etmiştir.

Öğretmenlerin video kulüp sürecinde yapılan tartışma toplantılarına yönelik deneyimlerini yansıtan görüşleri incelenmiş ve iki kategori altında toplanarak Tablo 4'te sunulmuştur. Öğretmenler görüşme sırasında, video kulüp tartışma toplantılarında kazandıkları deneyimlerden bahsederken aynı zamanda zorlandıkları yönleri de dile getirmişlerdir.

Tablo 4 Öğretmenlerin Video Kulüp Tartışma Toplantılarına Yönelik Deneyimlerini Yansitan Görüşleri

\begin{tabular}{lll}
\hline Kategoriler & Kodlar & Öğretmenler \\
\hline & Farklı bak1ş açıları geliştirme & Ö2, Ö3, Ö4, Ö5 \\
& Zaman1 verimli kullanma & Ö4 \\
& İş birliği içinde çalışma & Ö1, Ö2, Ö3, Ö4, Ö5 \\
& Meslektaş geribildirimi & Ö1, Ö2, Ö4, Ö5 \\
& Araştırmacı kimliği kazanma & Ö2 \\
& Öğrenciye odaklanma & Ö1, Ö2, Ö3, Ö4, Ö5 \\
& Öğrenci gözüyle bakma & Ö2, Ö3, Ö5 \\
& Sorgulama becerisi kazanma & Ö2, Ö4, Ö5 \\
& Öğretmen deneyimlerinden faydalanma Ö1, Ö2, Ö3, Ö4, Ö5 & Önleri \\
& Matematik eğitimcisinin kat1lım1 & Ö1, Ö5 \\
\hline \multirow{5}{*}{ Olumsuz yönleri } & Bir araya gelme zorluğu & Ö1, Ö2, Ö3, Ö4, Ö5 \\
& Toplantılların uzun sürmesi & Ö1, Ö2, Ö3, Ö4, Ö5 \\
& Ö1, Ö4
\end{tabular}

Tablo 4 incelendiğinde, öğretmenlerin tamamı video kulüp tartışma toplantılarının olumlu yönleri olarak daha çok iş birliği içinde çalışmalarını, öğrenciye odaklanmalarını ve 
birbirlerinin deneyimlerinden faydalanmalarını belirtmişlerdir. Ayrıca öğretmenler tartışma toplantılarını, farklı sınıf uygulamalarına yönelik birlikte değerlendirmeler yaparak dönütler verdikleri ortamlar olarak ele almışlardır. Tartışma toplantılarında sınıfın geneli yerine belirli öğrencilere odaklanmaya başladığını dile getiren Ö5 açıklamalarını şöyle yapmıştır: "bazı ögrenciler çok çabuk anlıyor öğrenmede sorun yaşamıyor ancak bazılarında durum de ğişiyor... Işste toplantılarda biz öğrenci fikirlerine dikkat etmeye, onlart anlamaya ve birlikte yorumlamaya çalıştık. " Bunun ile ilgili olarak Ö4 ise video derslerini ilk izlediği zamanlar daha çok öğretmenin sınıf yönetimine dikkat ettiğini ancak toplantılarda daha çok öğrenci yanıtları hakkında konuşmaya başladığından bahsetmiştir. Ö3 “...her birimize ayrı bir gözlem olanağ sağlaması ve bakış açılarımızı şekillendirmesiydi; yani artık öğrencinin gözünden olayı analiz edebiliyorduk." şeklinde açıklamalarını yaparak video kulüp toplantılarının öğrenci gözüyle olaylara bakma firsatı sağladığını ifade etmiştir. Diğer öğretmenlerden farklı bir noktaya değinen Ö2 ise kulüp toplantıları sayesinde öğrenci fikirlerini araştırarak, sorgulayarak ve yeni yöntemler keşfederek kendini bir araştırmacı olarak gördüğünden bahsetmiştir. Öğretmenlerin çoğu, video kulüp toplantılarını fikir alışverişinde bulundukları, farklı bakış açıları geliştirmelerine katkı sağlayan bir ortam olarak değerlendirmiştir. Bu yönde Ö5 "tartışma toplantılarında öğrencinin nasıl düşündüğünü anlamak için görüşlerimizi paylaştık. Birbirimizin deneyimlerinden faydalanarak aynı olaya farklı açılardan bakmaya başladık..." şeklinde görüşlerini ifade etmiştir. Ö1 ise "Birlikte değerlendirmeler yaparak uygulamalarımızı daha iyi nasıl yapabileceğimizi konuştuk. Öğrenci fikirlerini ele aldık neden böyle düşünmüş olabilir diye birlikte düşündük birlikte sorguladık. Böylece farklı öğretmenlerin bakış açılarını görme firsatımız oldu” şeklinde görüşlerini açıklamıştır. Video kulüp tartışma toplantılarına bir matematik eğitimcisinin katılmasını, toplantıların olumlu bir yönü olarak değerlendiren Ö1, bu durum ile ilgili görüşlerini şöyle dile getirmiştir: “...daha önce kullanmadığım bazı yöntemlerden bahsetti. Mesela eksik veri içeren sorular sorma üzerinde konuşmuştuk. Böylece ögrenci soruda verilenlerin eksik olduğunu fark edebilecek mi yoksa soruyu verilenler ile çözmeye mi çalışacak? Bunu görmek için bu tarz sorulara yer vermeye başladım." ifadelerini kullanarak matematik eğitimcisinin görüşlerinden faydalandığını belirtmiştir. Ö5 ise bu duruma yönelik "İzlediğimiz olaylar hakkında detaylı sorular sorarak dikkat etmediğimiz noktaların önemli ipuçları olduğunu anlamamızı sağladı.” şeklinde görüşlerini ifade etmiştir. Öte yandan tüm öğretmenler video kulüp tartışma toplantılarında bir araya gelme konusunda zorluk yaşadıklarından ve zaman yetersizliğinin bu durumu etkilediğinden bahsetmişlerdir. Örneğin, Ö4 "Çalışmada en çok yaşadı̆̆ımız sıkıntı bir araya gelmemiz oldu. Bana uyan zaman diğerine uymadı tek tek hepimizin müsait olduğu zamanları ayarlamak çok zor oldu. ” diyerek görüşlerini 
dile getirirken, Ö3 ise derslerin video kayıt altına alınması sırasında bir zorluk yaşamadıklarını ancak toplanma kısmında vakit yetersizliğinden dolayı zorluklar yaşadıklarını belirtmiştir. $\mathrm{Bu}$ tür öğretmen mesleki gelişimini destekleyen çalışmalar için okul yönetiminin destek sağlaması gerektiğini belirten Ö2, ders programlarının yoğunluğundan bahsederek bir araya gelmelerinde sorun yaşadıklarını dile getirmiştir. Bunun dışında, Ö1 ve Ö4 tartışma toplantıların uzun sürmesini olumsuz bir durum olarak değerlendirerek okuldaki gündelik rutin işlerinin yorucu olmasından bahsetmişlerdir.

Öğretmenlerin süreçle ilgili deneyimlerini yansıtan görüşleri alındıktan sonra, sürecin olumsuz yönlerinin giderilmesine yönelik alternatif çözüm önerileri sunmaları istenmiştir. $\mathrm{Bu}$ amaçla öğretmenlere görüşme sırasında, "Video kulüp deneyimleriniz sonucunda bu sürecin daha etkili tasarlanmasına yönelik önerileriniz nelerdir? sorusu yöneltilmiştir. Öğretmenlerin verdikleri yanıtlar analiz edilerek oluşturulan kategoriler ve kodlar Tablo 5'te verilmiştir.

Tablo 5 Öğretmenlerin Etkili Bir Video Kulüp Tasarımına İlişkin Görüşleri

\begin{tabular}{|c|c|c|}
\hline Kategori & Kodlar & Öğretmenler \\
\hline \multirow{3}{*}{$\begin{array}{l}\text { Okul-araştırmaci iş } \\
\text { birliği }\end{array}$} & Toplantı yeri ve zamanı ayarlanabilir & Ö1, Ö2, Ö3, Ö4, Ö5 \\
\hline & Ders programları düzenlenebilir & Ö1, Ö2, Ö3, Ö4, Ö5 \\
\hline & Öğretmen mesleki gelişimi desteklenebilir & Ö1, Ö2, Ö4 \\
\hline \multirow{6}{*}{$\begin{array}{l}\text { Öğretmen-araştırmac1 } \\
\text { iş birliği }\end{array}$} & Kavram öğretimi yapılabilir & Ö2 \\
\hline & Öğretmenlerin talep ve ihtiyaçları belirlenebilir & Ö1, Ö2, Ö5 \\
\hline & Farkl1 sınıf düzeyleri olabilir & Ö4 \\
\hline & Bir sınıf düzeyi olabilir & Ö2, Ö5 \\
\hline & Alternatif ölçme yöntemleri incelenebilir & Ö2 \\
\hline & Ders planları hazırlanabilir & Ö1 \\
\hline \multirow{3}{*}{$\begin{array}{l}\text { Kurumlar arası iş } \\
\text { birliği }\end{array}$} & Genelleştirilebilir & Ö3 \\
\hline & Sürdürülebilir & Ö1, Ö2, Ö3, Ö5 \\
\hline & Öğretmen eğitiminde kullanılabilir & Ö3 \\
\hline
\end{tabular}

Tablo 5 incelendiğinde, öğretmenlerin etkili bir video kulüp tasarımına yönelik önerileri; okul-araştırmacı iş birliği, öğretmen-araştırmacı iş birliği ve kurumlar arası iş birliği olmak üzere üç kategori altında toplanmıştır. Öğretmenlerin çoğu, daha verimli bir video kulüp sürecinin tasarlanmasında öncelikli olarak toplantı yerinin ve zamanının ayarlanmasından bahsetmiştir. $\mathrm{Bu}$ yönde Ö1 "zamanın daha iyi ayarlanması için okul desteğinin olması gerektiğini düşünüyorum.” görüşlerini dile getirirken Ö3 ise “...çalışmalar başlamadan okul ve araştırmacı birlikte düzenlemeler yapmalı kanaatindeyim. Zaman ve toplanma zorluğunun yaşanmaması açısından bunun gerekli olduğunu düşünüyorum.” şeklinde görüşlerini 
belirtmiştir. Ayrıca öğretmenler ders programlarının yoğun olmasının toplanma zamanlarının ayarlanmasında sorun olduğunu belirtmiştir. $\mathrm{Bu}$ durum ile ilgili olarak Ö5 görüşlerini şöyle açıklamıştır:“...ders programlarımızda müsait olduğumuz zamanı ayarlamaya çalıştık. Ancak boş derslerimiz birbirine uymadı. Bu sıkıntının olmaması için okul idarecileri çalışmaya katılan ögretmenlerin ders programlarında en azından bir saati denk getirebilir.” Bunun dışında öğretmenlerden üçü, mesleki gelişim için okul yönetiminin öğretmenleri teşvik edici uygulamalar yürütmesi gerektiğinden bahsetmiştir. Örneğin, Ö2 “Okulların bu çalışmalar için öğretmenlerini desteklemesi lazım. Okul idarecileri zümre öğretmenlerin birlikte çalışması için zaman ayırmall. Seminer dönemlerinde de olabilir ya da haftada bir saat ayarlanabilir..." görüşlerini ifade etmiştir. Bu öneriler doğrultusunda, araştırmacı ile okulun iş birliği içerisinde süreci yürütmeleri konusunda öğretmenlerin hem fikir oldukları söylenebilir. Öte yandan öğretmenler kulüp çalışmalarının kendi istek ve ihtiyaçları doğrultusunda tasarlanmasının daha etkili olacağını ileri sürmüşlerdir. $\mathrm{Bu}$ anlamda, öğretmenler konu seçiminin birlikte yapılmasının önemli olduğunu ifade etmişlerdir. Örneğin Ö4 “Farklı konular anlatılabilir. Hangi konuların olacağına birlikte karar verebiliriz. Farklı sınıf düzeyindeki konularda ögrencilerin nasıl düşündüklerini inceleyebiliriz." ifadeleriyle görüşlerini belirtmiştir. Buna karşılık, Ö2 "Aynı konu ve sorular birlikte belirlenerek bir sınıfta işlendikten sonra ögretmenlerle geniş bir zamanda incelenip yorumlanabilir. Eksiklikler not alınıp başka bir sınıfta tekrar aynı dersin incelenmesi, yapılan yorumların ne kadar katkı sağladiğı açısından iyi olabilir." ifadelerini kullanmıştır. Dolayısıyla Ö4 farklı sınıf düzeyindeki konuların ele alınması gerektiğini belirtirken Ö2 aynı konuların bir sınıf düzeyinde ele alınması gerektiğini savunmaktadır. Ancak iki öğretmen de konuların birlikte seçilmesi gerektiği üzerine hemfikirdir. Buna ek olarak Ö2, video kulüplerin kavram öğretimine yönelik tasarlanmasından bahsetmiştir. Ö2'ye göre konu yerine kavramlar ele alınabilir. Çünkü konunun anlaşılması için kavramların öğrenilmesi gerekmektedir ve öğrencilerin öncelikle kavramlar hakkındaki düşüncelerinin ortaya çıkarılması daha önemlidir. Yine Ö2 “Dersin sonunda kullanacă̆ımız küçük sınavlar ya da farklı yöntemler ile kavramların öğrenciler açısından ne kadar anlaşıldı̆̆ belirlenebilir. Daha sonra bu sinavlar ögretmenlerle incelenerek neler yapllabilir diye tartışılabilir." görüşlerini dile getirerek alternatif ölçme yöntemlerinin birlikte incelenmesini önermiştir. Bunun yanı sıra Ö1, öğrencinin öğrenme zorluğu çektiği konular belirlenerek meslektaşları ile birlikte ders planlarının hazırlanmasının etkili olabileceğini belirtmiştir. Öğretmenlerin video kulüplerin sürdürülebilir olması, genelleştirilmesi ve öğretmen eğitiminde kullanılmasına yönelik önerileri kurumlar arası iş birliği kategorisi altında sınıflandırılmıştır. Öğretmenlerin çoğu, mesleki gelişim faaliyetlerinin etkili olabilmesi için sürdürülebilir 
olmasının gerekli olduğunu ifade etmiştir. $\mathrm{Bu}$ anlamda Ö5 “...sadece belli bir süre ile sınırlandırılmamall, devamlılığı olmalı. Birlikte tartışıp birlikte araştırıp sınıflarımızda uygulamamız çok keyifli...” şeklinde görüşlerini belirtmiştir. Ö3 ise video kulüplerin genelleştirilmesi önerisinde bulunmuş ve görüşlerini şöyle belirtmiştir: "Bu uygulama genelleştirilip tüm eğitim kurumlarında programlanmış bir etkinlik olabilir. Gerek öğretmen yetiştirmede gerekse ögretmen gelişiminde etkili bir uygulama olarak kullanılabilir.” Benzer olarak, Ö2 işbirliği içinde çalışmanın motivasyonlarını artırdığını söyleyerek kulüp uygulamalarının belirlenen ihtiyaçlar doğrultusunda sürekli yapılması gerektiğini belirtmiştir.

\section{Sonuç ve Tartışma}

$\mathrm{Bu}$ çalışma, video kulüp sürecine katılan ortaokul matematik öğretmenlerinin süreç ile ilgili deneyimlerini yansıtmak amacıyla gerçekleştirilmiştir. Çalışmada ilk olarak video kulüplerin öğretmenlerin mesleki gelişimine yönelik katkıları incelenmiştir. Katılımcı öğretmenlerin mesleki gelişimlerine yönelik belirttikleri görüşlerden video kulüplerin öğretmenlerin fark etmelerini, öğrenciyi tanımalarını, duyarlı öğretim uygulamalarını ve öğretmenin öğrenmesini desteklediği söylenebilir. Konuyla ilgili yapılan birçok araştırma, video kulüplerin öğrencinin düşünmesini fark etme ve yorumlamaya yönelik öğretmen becerilerini geliştirdiğini göstermektedir (Jacobs, Lamb \& Philipp, 2010; Sherin \& Han 2004; Sherin \& van Es, 2005; Sherin \& van Es, 2009; van es \& Sherin, 2008). Buradan da anlaşılacağ1 gibi öğretmenlerin görüşlerinden elde edilen bulgular konu bazında yapılan bu araştırma bulgularını desteklemektedir. Katılımcı öğretmenlerin görüşme sırasında en detaylı açıklamaları öğretim uygulamalarına yönelik yaptıkları görülmüştür. Öğretmenlerin görüşlerinden öğrenci odaklı bir yaklaşım benimseyerek duyarlı öğretim uygulamalarını geliştirdikleri anlaşılmaktadır. Benzer bir sonuca van Es ve Sherin (2010) çalışmalarında rastlanmaktadır. van Es ve Sherin (2010) çalışmalarında video kulübe katılan matematik öğretmenlerinin sınıf içi uygulamalarında "öğrenci fikirlerine daha fazla yer açma”, "öğrenci düşünmesini araştırma" ve “öğretim sırasında öğrenci fikirlerini öğrenme” şeklinde üç değişiklik meydana geldiğini ortaya koymuşlardır. $\mathrm{Bu}$ çalışmada da öğretmenlerin görüşlerinden öğrencilerin fikirlerini önemseyerek açığa çıkarmaya çalıştıkları, öğrencilerin nerede ve nasıl düşündüklerini öğrenmek için sorgulayıcı bir yaklaşım geliştirdikleri anlaşılmaktadır. Ayrıca katılımcı öğretmenler, video kulüp çalışmalarının öğrencilerin öğrenme güçlüklerini ve ön öğrenmelerini belirlemede etkili olduğunu düşünmektedirler. Bu durum öğretmenlerin video kulüp toplantılarında öğrenci düşünmesine odaklanarak öğrenciyi daha 
yakından tanımaya çalışmalarının bir sonucu olarak düşünülebilir. Öte yandan öğretmenlerin video kulüplerin mesleki gelişime katkısına yönelik görüşleri öğretmenin öğrenmesini desteklediği yönündedir. Özellikle bu kategori altında öğretmenlerin daha çok fark etme ve sorgulamayı öğrendiklerine ilişkin görüşler belirttikleri görülmüştür. $\mathrm{Bu}$ bulgu, video kulüplerin öğretmenlerin analitik düşüncelerini ortaya çıkarmak için kullanılan verimli bir süreç olduğunu gösteren araştırma sonuçlarıyla (Luna \& Sherin, 2017; van Es \& Sherin, 2008) paralellik göstermektedir.

Video kulüp sürecinde kendi sınıf videolarını analiz etme deneyimlerine yönelik öğretmenlerin görüşleri incelendiğinde, özellikle öz değerlendirme ve öz eleştiri yapma konusunda hem fikir oldukları görülmektedir. Zhang ve diğerlerine (2011) göre öğretmenlerin kendi videolarını izleyerek değerlendirmelerde bulunmaları, sınıflarını farklı açılardan görmelerinde etkili olmaktadır. Yine Seidel ve diğerlerinin (2011) araştırması, öğretmenlerin kendi ders videolarını izleyerek analiz etmelerinin onlara daha etkin bir deneyim sağladığını göstermektedir. Buna karşılık, öğretmenlerin kendi dersleri üzerine yansıtıcı olmaktan kaçınma ihtimallerinin olması olumsuz bir durum olarak karşımıza çıkmaktadır. $\mathrm{Bu}$ durum, öğretmenlerin kendi uygulamalarına yönelik objektif değerlendirme yapmalarının önüne geçmektedir. Oysa ki öğretmenlerin kendi videolarını analiz etmelerindeki amaç öğrenci düşünmesi ile kendi sınıf uygulamaları arasında bağlantılar kurarak alternatif çözüm stratejileri geliştirebilmeleridir.

Katılımcı öğretmenler, meslektaşlarının videolarını analiz etmelerinin farklı öğretim uygulamalarını gözlemleme ve karşılaştırma yaparak değerlendirme fırsatı sağladığını düşünmektedirler. Benzer olarak, Zhang ve diğerleri (2011) çalışmalarında öğretmenlerin farklı ders videolarını izleyerek kendi öğretimleriyle karşılaştırmalar yaptıklarını ve başka teknikleri özümseyerek öğretimlerini değiş̧tirdiklerini ortaya koymuşlardır. Öğretmenlerin çoğu, meslektaşlarının sınıf videolarını analiz etmelerinin eleştirel bir duruş geliştirmelerine yardımcı olduğunu düşünmektedir. Buna karşılık, Seidel ve diğerlerinin (2011) çalışmaları öğretmenlerin göre tanımadıkları meslektaşlarının ders videoları hakkında daha fazla tartışmalara dahil olduklarını ve eleştirel söylemlerde bulunduklarını göstermektedir. Her ne kadar öğretmenler meslektaşlarının sınıf videolarını analiz etmelerinin olumlu yönlerinden bahsetmiş olsalar da, yaşadıkları zorlukları belirtmeyi ihmal etmemişlerdir. Ancak dikkat çekici olan öğretmenlerin bu zorlukları kendi video analizleri için dile getirmemiş olmalarıdır. Bu durum videoda belirledikleri olumsuzlukların kendi sınıf videoları için geçerli olmadığını hissetmelerinden (Beisiegel vd., 2018; Kleinknecht \& Schneider, 2013) kaynaklanabilir. 
Video kulübe katılan öğretmenlerin tartışma toplantılarına yönelik görüşleri incelendiğinde daha çok iş birliği içinde çalışma, birbirlerinin deneyimlerinden faydalanma ve öğrenciye düşünmesine odaklanma deneyimlerine katkı sağladığını düşünmektedirler. Ayrıca öğretmenlerin çoğu toplantılar sayesinde farklı bakış açıları oluşturduklarını, öğrenci gözüyle bakmaya başladıklarını ve sorgulama becerisi kazandıklarını belirtmiştir. Sherin’a göre (2003) video kulüpler öğretmenlere birlikte çalışma firsatları sunması ve gerçek sınıf uygulamalarıyla bağlantılı olması yönünden etkili bir mesleki gelişimin iki özelliğini de içermektedir. Bu yönde Wallin ve Amador (2019) ise video kulüplerin öğretmenlerin iş birliği içinde çalışmalarını olumlu yönde etkilediğini ileri sürmektedir. Dolayısıyla elde edilen bulgular bahsi geçen araştırma sonuçları ile paralellik göstermektedir. $\mathrm{Bu}$ anlamda video kulüp toplantıları öğretmenlerin iş birliği içinde çalışmalarını sağlayarak kendi ve meslektaşlarının öğretim uygulamalarını farklı bakış açılarıyla değerlendirmelerine firsat vermektedir. Öğretmenler kulüp toplantılarında videolar ve birbirleriyle etkileşimlerinin sonucunda öğrenci düşünmesi hakkında daha fazla bilgi sahibi olabilirler (Borko vd., 2008). Böylece öğretmenler öğrenci düşünmelerini anlamak ve yorumlamak için öğrenci gözüyle analizlerini yapabilirler. Bunun yanı sıra katılımcı öğretmenler, video kulüp tartışma toplantılarının olumsuz yönlerinin de olduğunu belirtmişlerdir. Öğretmenlerin dile getirdikleri olumsuz görüşlerin daha çok bir araya gelme ve zaman yetersizliği hakkında olduğu anlaşılmaktadır. Nitekim belirtilen bu zorluklar sadece video kulüp için değil öğretmenlerle yürütülen mesleki gelişim süreçleri (örneğin, ders imecesi modeli) için de söz konusudur.

Öğretmenlerin etkili bir video kulüp tasarımına yönelik görüşleri oldukça kapsamlıdır. Öğretmenler bu durum ile ilgili görüşleri araştırmacıların, öğretmenlerin ve okulların iş birliği içerisinde çalışmaları yönündedir. Öğretmenlerin tümü, mesleki gelişim uygulamalarına katılmaları için okul desteğinin olması gerektiğini düşünmektedir. Bunun için araştırmacı ve okulun birlikte hareket ederek toplantı yerinin, saatinin belirlenmesini ve ders programlarının düzenlenmesini önermektedirler. Öte yandan öğretmenler video kulüp çalışmalarının daha etkili olabilmesi için öğretmenlerin istek ve ihtiyaçları doğrultusunda tasarlanmasının gerekli olduğu görüşündedirler. $\mathrm{Bu}$ yönde, video kulüplerin öğretmen ve öğretmen eğitimcilerinin ihtiyaçları ve amaçları doğrultusunda uyarlanabilen esnek bir yapıya sahip olduğunu gösteren araştırmalar da vardır (Barnhart \& van Es, 2020; Borko vd., 2011). Ayrıca öğretmenler video kulüp uygulamalarının okullarda sürdürülebilir olması yönünde önerilerde bulunmuşlardır. Bununla birlikte bu uygulamaların genelleştirilmesi ve öğretmen eğitiminde kullanılması 
konusunda da görüşlerini belirtmişlerdir. Öğretmenlerin bu görüşleri video kulüp modelinin okullarda uygulanabileceğinin bir göstergesi olarak düşünülebilir.

\section{Öneriler}

Çalışmadan elde edilen bulgular, video kulüplerin etkili bir mesleki gelişim modeli olarak kabul görmesini desteklemektedir. Özellikle video kulüplere yönelik en doğru değerlendirmeleri sürece katılan öğretmenlerin yapabileceği düşünüldüğünde, bu çalışmanın gelecekte farklı video kulüplerin tasarlanmasına ilişkin yapılacak uygulamaların yaygınlaştırılmasında etkili olacağı düşünülmektedir. Öğretmenlerin görüşleri her ne kadar video kulüp sürecinin olumlu özelliklerini yansıtsa da olumsuz olarak değerlendirilen yönlerin de ele alınması gerekir. $\mathrm{Bu}$ açıdan baktığımızda, sürecin olumsuz yönlerine ilişkin öğretmenlerin dile getirdikleri alternatif çözüm önerileri dikkate alınabilir. Öğretmenlerin de belirttiği gibi bir araya gelme ve zaman yetersizliği konusunda okul yönetiminin desteği sağlanabilir. Böylece okul ve araştırmacı işbirliği içinde video kulüp çalışmalarının yürütülmesi öğretmenlerin çalışma motivasyonlarını artırabilir. Ayrıca öğretmenlerin önerisi doğrultusunda video kulüp uygulamaları tasarlanmadan önce öğretmenlerle iş birliği yapılarak talep ve ihtiyaçları belirlenebilir. Bu durum, öğrencilerin öğrenme güçlüğü çektikleri kavramların öğretiminde etkili olabileceği gibi öğretmenlerin de farklı uygulamalar geliştirmelerinde faydalı olabilir. 


\title{
A PHENOMENOGRAPHY RESEARCH REFLECTING THE EXPERIENCES OF TEACHERS ATTENDING THE VIDEO CLUB
}

\author{
Gülşah Özdemir Baki ${ }^{1}$ \\ ${ }^{1}$ Atatürk Üniversitesi, Oltu Beşeri ve Sosyal Bilimler Fakültesi, Maliye Bölümü \\ gulsah.baki@atauni.edu.tr, http://orcid.org/0000-0002-1497-6528 \\ Gönderme Tarihi: 10.09.2020 \\ Kabul Tarihi: 16.11 .2020
}

Doi: $10.17522 /$ balikesirnef.793164

\begin{abstract}
Video club, which is a video-based professional development model, is a process in which a group of teachers watch class videos of themselves or their colleagues and develop discussions about the situations they noticed. This research reflects the views of five middle school mathematics teachers who joined the video club in order to improve their professional vision. Therefore, this research has been developed within the framework of a phenomenographic research approach. The data of the research were obtained from semi-structured interviews with teachers and subjected to content analysis. The data obtained from the interviews with teachers showed that the video club process supports teachers' noticing, student recognition, sensitive teaching practices and learning. In this sense, it can be said that video clubs have a positive effect on teachers' professional development. This situation can be considered as an indication of the flexible applicability of video clubs compared to other professional development programs. In addition, the views of the teachers reflecting their own and their colleagues' experiences in analyzing classroom videos were presented, and their suggestions for an effective video club design were presented. Future studies in line with teacher suggestions can be investigated how the video club activities can show continuity to create the desired effects in professional development practices.
\end{abstract}

Key words: Teacher professional development, professional development models, video club, mathematics teacher

Corresponding author: Gülşah Özdemir Baki, gulsah.baki@atauni.edu.tr

\section{Introduction}

With the beginning of education becoming institutionalized in human history, the teacher has always been one of the important components of teaching. The role of the teacher in the society and the qualifications it should have started to be discussed under the title of professional competencies of the teacher. While this debate has survived until today, it has found a wide place in mathematics education. Professional competencies of teachers form an 
integrity by incorporating the professional knowledge, skills, attitudes and values that they should have in order to carry out their profession effectively (MEB, 2017). As a matter of fact, the continuous change of the social life we live in requires teachers to constantly question and improve their professional competencies. This situation clearly reveals the importance of professional development processes that enable teachers to improve themselves. A quality professional development is a central component of almost every modern program for the development of education. In this respect, Guskey 's (2002) model for the teacher change process primarily involves improving student learning so that there is a significant change in teachers' attitudes and beliefs. These improvements are possible with learning tools to develop teachers' sensitive teaching practices.

The use of video emerges as an internationally widespread practice to support teachers' professional development (Christ, Arya \& Chiu, 2017). New developments in video technology, especially video tagging, editing and sharing, are making widespread use of video in teacher education (Gaudin \& Chaliès, 2015). Video used as an effective learning tool can show the complexity of classroom practices and make student thinking visible (Barnhart \& van Es, 2015; Santagata \& Yeh, 2013). In addition, it can capture important class events that teachers do not pay attention and allows to examine class interactions by monitoring them again whenever desired (Brophy, 2004). In this respect, videos also allow teachers to observe their own or colleagues' teaching practices (Borko, Jacobs, Eiteljorg \& Pittman, 2008; Seago, 2004; Sherin \& van Es, 2009). Video being an important learning tool leads to the use of various video-based programs by teacher educators and professional program developers to support teacher learning. (e.g., Amador, Keehr, Wallin \& Chilton, 2020; Goldsmith \& Seago, 2011; Sherin \& van Es, 2005; Schifter, 2001).

Studies investigating the role of video in mathematics teaching were generally concerned with what teachers should learn from classroom interactions (Sherin, 2004). In this direction, the video club model draws attention with its use especially in mathematics teaching in order to enable teachers to recognize and interpret the important features of classroom interactions.

\section{Video Club Model}

Video club is a process in which a group of teachers develop reflective discussions about the situations they or their colleagues notice by watching video lessons. The video club model, which has recently increased its popularity in mathematics and science education, is accepted as a learning process used to support teachers' sensitive teaching practices and to reveal their analytical thoughts (Luna \& Sherin, 2017; Sherin \& Han, 2004). In this process, a group of 
teachers carefully monitor the important interactions that occur in the classroom through class videos of their own or colleagues, and evaluate how these interactions affect students' learning. (Santagata \& Yeh, 2013). The most important feature that distinguishes video clubs from other professional development environments is that the participants in this process learn how to interpret the events that take place in the classroom and reflect them on their teaching, rather than what they will do in the classroom (Sherin, 2004, p. 14).

In general a video club is created with the participation of teachers and researchers for a specific purpose. At the video club meeting, teachers watch one or more video sections and develop discussions about the situations they notice. Meanwhile, the researcher takes the role of facilitator at each video club meeting, leading the group to watch the video lesson by summarizing which class level and related subject. In addition, according to the purpose of the club meeting, facilitator helps the teachers to develop their discussions by directing them. For example, in a video club designed to notice students' mathematical thinking, the aim of the facilitator is to help teachers learn to notice and interpret their mathematical thinking. In this respect, the video club helps teachers to make sense of classroom interactions (Star \& Strickland, 2008; van Es \& Sherin, 2008) and focuses on student mathematical thinking (Sherin \& Han 2004; Sherin \& van Es 2009; Jacobs, Lamb \& Philipp, 2010). At the same time, video clubs provide the opportunity for teachers to develop different perspectives for themselves and their colleagues' classroom practices by listening to each other's ideas, trying to understand them, and putting forward opposite ideas.

Research results on the subject show that video clubs encourage teachers to move from partial, non-detailed descriptive analysis to more focused, detailed and interpretive analysis (e.g., Sherin \& Han, 2004; Sherin \& van Es, 2005; van Es \& Sherin, 2008). In this respect, Jilk (2016) explained the video club as a component of a multidimensional professional development network model aimed at the re-culture of mathematics classes. In addition, in the study of Jilk, teachers examined the change in the way students see and talk about mathematical activities through the video club. According to Jilk (2016), none of the other learning areas included in the model give both program facilitators and mathematics teachers the opportunity to observe the same classroom activities at the same time. However, the video club provides this opportunity to both teachers and facilitators. Stürmer, Königs and Seidel (2012) showed that video-based professional development programs are more effective than traditional courses. Also related to the subject, Barnhart and van Es (2020) investigated how teachers developed a critical discourse in the context of the video club. As a result of the research, it was 
seen that the teachers who participated in the video club developed more collaborative, interpretive and evidence-based discourses about teaching and learning. On the other hand, Wallin and Amador (2019) investigated how the content of teachers who participated in a video club designed to recognize student thinking affects their pedagogical design capacities. As a result of their work, they revealed that the video club process affects teachers' pedagogical design capacities and collaborative views. In addition, it has been observed that teachers' ability to notice and use student thinking has improved.

Researches in the literature show that video clubs are designed to include different learning objectives. In this direction, some research is concerned with analyzing the situations teachers notice (e.g., Star \& Strickland, 2008; van Es, 2011); some research has dealt with teachers' understanding and interpretation approaches to student mathematical thinking (e.g., Beisiegel et al., 2018; Goldsmith \& Seago, 2011; Jacobs et al. 2010; Luna, Selmer \& Rye, 2018 Sherin \& van Es 2009; van Es \& Sherin 2008) and some have discussed changes in teachers' teaching practices (e.g., Borko, Koellner \& Jacobs, 2014; Borko, Koellner \& Jacobs, 2017; Sun \& van Es, 2015). In the related literature, there are also studies showing that the video club, which is a professional development model, is an efficient process to support the professional visions and development of teachers (Seago, 2004; Seidel, Stürmer, Blomberg, Kobarg \& Schwindt, 2011; Sherin, 2004; Sherin \& van Es, 2005; Sherin \& van Es, 2009; van Es, 2011; van Es, Cashen, Barnhart \& Auger, 2017). Therefore, it is important for the professional development of teachers to reveal the applications that facilitate working with mathematics teachers by using video (Coles, 2019). Similarly, Borko et al. (2014) suggest that teachers have facilitating effects with their colleagues in the process of professional development. The flexible structure that video clubs can adapt to the needs of teachers (Borko, Koellner, Jacobs \& Seago, 2011) enables it to play an important role in teacher education. In this respect, club work is accepted as a method that stimulates teachers' sensitive teaching practices. (TekkumruKisa and Stein, 2017; Zhang, Lundeberg, Koehler \& Eberhardt, 2011). This clearly reveals the importance of the video club model for the professional development of teachers.

On the other hand, in the related literature, there are a few researches that discuss the views of teachers participating in video clubs to improve their professional vision. In this regard, van Es and Sherin (2010) examined the views of teachers who participated in the video club about the teaching practices. Similarly, Özdemir-Baki and K1lıçoğlu (2020) examined the changes in classroom practices of middle school teachers who participated the video club. In their studies, they also included the views of teachers about their practices. In this study, the 
scope of the study was expanded by taking the views of teachers about the different dimensions (contribution to professional development, analyzing peer-class videos, analyzing own classroom videos, video club meetings, effective video club design) of the video club process. Increasing the quality of a professional development process can only be possible with the views and thoughts of the teachers involved in the process. Because they are teachers who are in a position to offer alternative solutions by making the best evaluations about the process. From this point of view, it is thought that the teachers participating in the video club can make the most realistic evaluations about the process and share solution-oriented suggestions to be applicable. Moreover, teachers' views and thoughts are very important in maintaining video clubs in a way that can make the desired effects on the professional development of teachers. The problem of working under this perspective is as follows:

What are the views of middle school mathematics teachers who are involved in the video club professional development process?

\section{Method}

\section{Research Design}

This study was developed within the framework of phenomenographic research approach. Phenomenography is a research approach designed to answer specific questions about thinking and learning (Marton, 1986), and is included in the qualitative research tradition (Trigwell, 2006). The aim of phenomenographic research is to investigate the different ways individuals make in understanding or conceptualizing experiences related to a particular aspect of a phenomenon (Marton, 1986). In other words, it is to describe the phenomenon as perceived by individuals. Therefore, the focus of this research method is subjective experiences of individuals. In educational studies, it is used for the purposes of interpreting the nature of the individual's experiences and developing learning and teaching (Akerlind, 2002). This study is a phenomenographic research since it was designed to reflect the experiences of a group of secondary school mathematics teachers involved in the video club process.

\section{Participants}

This study, which is working in a state secondary school in the east of Turkey was carried out with five female math teacher. In phenomenographic researches, the participants should have experienced experiences related to the researched phenomenon. For this reason, the 
working group consists of teachers who are involved in the video club process conducted by the researcher in the spring term of the 2018-2019 academic year. The professional experience of the participant teachers varies between six and fifteen years. Due to the ethics of the research, coding such as Ö1, Ö2, Ö3, Ö4 and Ö5 were used instead of the real names of the teachers.

\section{Video Club Process}

A video club was created with the participation of participating teachers, researchers and a mathematics educator. The lesson of a teacher was recorded in the video club meeting by the researcher every week. Video club participants came together once a week in the school where the teachers worked. The teachers carefully watched the video lessons recorded cyclically and developed discussions about the situations they noticed. At the same time, while the teachers were watching the video lesson, they made evaluations about their own and their colleagues' teaching practices. Video club meetings continued about an hour. The researcher was a facilitator in video club meetings, asked questions to learn more about the situations teachers noticed and enabled them to focus on student mathematical thinking. One month after the completion of eleven weeks of video club practices, meetings were held with the teachers to reflect their experiences about the process.

\section{Data Collection}

The data of this research was obtained from semi-structured interviews with teachers after the video club process. A semi-structured interview form has been prepared by the researcher to reflect teacher experiences for the video club process. This form consists of five open-ended questions. The first question has been prepared to determine the views of teachers regarding the contribution of the video club process to teacher professional development. The second and third questions reveal the teachers 'experiences for watching and evaluating their own and colleagues' videos. Another question was created to reflect teacher experiences for video club discussion meetings. The final question includes teachers' suggestions for designing a more effective video club process. After the interview questions were prepared, the views of two experts who were experts in their fields were taken and necessary arrangements were made. For example, in the first question, the expression "contributions" was changed to "their contribution to your professional development". Afterwards, the interview questions were evaluated with two mathematics teachers who were not included in the study and it was determined that the questions were understandable. While collecting the research data, approximately 30 minutes of interviews were made with each teacher and these interviews were recorded using a video 
camera. Before the analysis was done, the data obtained from the interviews were written in computer environment and voice transcripts of five teachers were created separately. Teachers who participated in the interview were asked to confirm, to check the accuracy and authenticity of verbal speeches converted into written text.

\section{Data Analysis}

In this study, the data obtained from semi-structured interviews with teachers were subjected to content analysis. The aim of content analysis is to conceptualize the data collected and to organize the emerging concepts to make them understandable to explain the data (Yıldırım \& Şimşek, 2016). For this aim, firstly, the data obtained from semi-structured interviews were tried to be made meaningful in itself. At this stage, firstly, the draft codes of the data were formed by determining the similarities and differences in the expressions of the teachers. A list of these draft codes was prepared. The data obtained were reviewed by the researcher two weeks later, and the codes were edited. Later related codes are classified under certain categories.

In the study, detailed information was collected through face-to-face interviews with teachers and descriptions were included in the export of the obtained data. On the other hand, every interview with teachers was converted into written text and teachers were asked to confirm their accuracy. Finally, the coding categories obtained in the analysis of the data were examined by two mathematics educators and their consistency was checked with teacher responses. Some codes expressing the same situation were combined in line with the suggestions of mathematics educators. For example; by combining the codes "determining activities according to student level" and "descending student level", a code of "considering student level" was created. In addition, three suggestions were obtained by classifying teacher suggestions.

\section{Results}

The categories and codes were created by analyzing the data obtained from the interviews made with the participating teachers regarding the professional development process of the video club. The coding categories created for each question were presented in tables. During the interview, the researcher asked "What do you think the contributions of the video club process to your professional development? Analyzes of teachers' responses are given in Table 1. 
Table 1 Teachers' Views Reflecting Video Club Professional Development Experiences

As seen in Table 1, the contributions of the video club process to the professional development of teachers were collected under four categories. Noticing category consists of four codings that include the situations that teachers focus on and try to understand. All of the teachers stated that video clubs were effective in focusing on student thinking. Regarding this, T3 expressed her views as follows: "First of all, I started to pay attention to the students' ideas.

I tried to understand why he/she was thinking that way. " On the other hand, Ö1 stated that she

\begin{tabular}{|c|c|c|}
\hline Categories & Codes & Teachers \\
\hline \multirow{4}{*}{ Noticing } & Focus on student ideas & $\mathrm{T} 1, \mathrm{~T} 2, \mathrm{~T} 3, \mathrm{~T} 4, \mathrm{~T} 5$ \\
\hline & Interpreting the student's thinking & $\mathrm{T} 1, \mathrm{~T} 2, \mathrm{~T} 4, \mathrm{~T} 5$ \\
\hline & Paying attention to classroom interactions & $\mathrm{T} 1, \mathrm{~T} 2, \mathrm{~T} 3, \mathrm{~T} 4$ \\
\hline & Making sense of class interactions & $\mathrm{T} 1, \mathrm{~T} 5$ \\
\hline \multirow{5}{*}{$\begin{array}{l}\text { Student } \\
\text { recognition }\end{array}$} & Identifying misconceptions & $\mathrm{T} 1, \mathrm{~T} 2, \mathrm{~T} 3, \mathrm{~T} 5$ \\
\hline & $\begin{array}{l}\text { Questioning the prior knowledge of the } \\
\text { student }\end{array}$ & $\mathrm{T} 1, \mathrm{~T} 2, \mathrm{~T} 4$ \\
\hline & Predicting learning difficulties & $\mathrm{T} 1, \mathrm{~T} 2, \mathrm{~T} 3, \mathrm{~T} 4$ \\
\hline & Guessing student questions & $\mathrm{T} 2, \mathrm{~T} 4, \mathrm{~T} 5$ \\
\hline & Predicting student responses & $\mathrm{T} 1$ \\
\hline \multirow{14}{*}{$\begin{array}{l}\text { Sensitive teaching } \\
\text { practices }\end{array}$} & Using different teaching methods & $\mathrm{T} 1, \mathrm{~T} 2, \mathrm{~T} 4, \mathrm{~T} 5$ \\
\hline & Caring about student ideas & $\mathrm{T} 1, \mathrm{~T} 2, \mathrm{~T} 4$ \\
\hline & Revealing student ideas & $\mathrm{T} 4, \mathrm{~T} 5$ \\
\hline & Ensuring the participation of the student & $\mathrm{T} 2, \mathrm{~T} 4, \mathrm{~T} 5$ \\
\hline & Making sure the student understands & $\mathrm{T} 4$ \\
\hline & Teacher feedback & $\mathrm{T} 1, \mathrm{~T} 2, \mathrm{~T} 4, \mathrm{~T} 5$ \\
\hline & Creating norms & $\mathrm{T} 1$ \\
\hline & Paying attention to student level & $\mathrm{T} 2, \mathrm{~T} 3, \mathrm{~T} 4, \mathrm{~T} 5$ \\
\hline & Approach to the student & $\mathrm{T} 1, \mathrm{~T} 3, \mathrm{~T} 4, \mathrm{~T} 5$ \\
\hline & Questioning student thinking & $\mathrm{T} 1, \mathrm{~T} 2, \mathrm{~T} 4, \mathrm{~T} 5$ \\
\hline & Material selection & $\mathrm{T} 1, \mathrm{~T} 4, \mathrm{~T} 5$ \\
\hline & Allow time & $\mathrm{T} 1, \mathrm{~T} 4$ \\
\hline & Supporting the student for different solutions & $\mathrm{T} 1, \mathrm{~T} 4$ \\
\hline & Allowing the student to make mistakes & $\mathrm{T} 2, \mathrm{~T} 4$ \\
\hline \multirow{4}{*}{ Teacher's learning } & $\begin{array}{l}\text { Learning to focus on causes rather than } \\
\text { results }\end{array}$ & $\mathrm{T} 2$ \\
\hline & Learning while teaching & $\mathrm{T} 4$ \\
\hline & Learning to question & $\mathrm{T} 2, \mathrm{~T} 5$ \\
\hline & $\begin{array}{l}\text { Learning the discourses that cause } \\
\text { misconceptions }\end{array}$ & $\mathrm{T} 1, \mathrm{~T} 2, \mathrm{~T} 3$ \\
\hline
\end{tabular}


focused on student ideas with the statement "I saw that the students actually had different ideas but they could not express this clearly." In addition, the teachers provided views stating that they focused on students' ideas and tried to understand and interpret these ideas. For example, T2 explained her thoughts about this as "I noticed that the students had wrong thoughts even under their correct answers, and sometimes I noticed that there were different thoughts or perspectives under the wrong answers." T4 stated that video clubs improved their understanding and interpretation of many events in the classroom and talked about the situations they noticed regarding classroom interactions.

Student recognition category covers the activities teachers do to get to know the student better. In this category, most teachers expressed their views on identifying students' learning difficulties and misconceptions. Teachers think that video clubs are an effective way to identify students' misconceptions. In this context, T5 stated that students started to guess their misconceptions during the video club process, while T2 stated that she realized what misconceptions might arise in terms of students while watching the videos. In addition, T2 stated her ideas that "I think students' prior knowledge is important and we need to check it at the beginning of each lesson. Thus, it may be easier for us to identify misconceptions." Most of the teachers stated that they started to predict students' learning difficulties while analyzing the classroom videos. For example, T3 explained that "I think that my prediction has improved about in which concepts, where and how students can make mistakes and in which concepts they may have difficulties." T4 stated that the students had more difficulty in geometry and therefore preferred the way of memorization. Three of the teachers (T2, T4, T5) stated that the video club process improved their ability to predict student questions, whereas $\mathrm{T} 1$ stated that they improved the ability to predict student answers. Regarding this situation, T1 stated that "I started to guess what the student responded to the question of the teacher while watching the video without watching it". It is understood from the views of the teachers that they try to get to know the students better by trying to determine the students' prior knowledge, misconceptions and learning difficulties during the video club.

It is a remarkable finding that the views of the teachers participating in the video club about classroom practices are quite detailed. Teachers' responses show that they adopt more student-centered approaches in teaching practices. Therefore, these approaches of the teachers were gathered under the category of sensitive teaching practices. In this category, teachers generally stated that they started to use different methods, they care more about student ideas, they try to reveal students' ideas, they question students' ideas for this, they use activities to 
ensure students' participation in the lesson, they consider the student level in the selection of these activities and they try to choose the appropriate materials. T5 explained her views about this as follows: "I saw that I started with higher level questions and other teachers solved simpler questions. I noticed that even my first examples were difficult... I start the lesson by giving simpler examples. " T4 said, "I realized that I thought which material I should use while going to the classroom. I ask my teacher friends what materials they have used..." and stated the importance she gave to the material selection. Expressing that $\mathrm{T} 1$ started to use different teaching methods, she stated that the teachers focused on different methods while evaluating the classroom videos and started to use them in their own lessons. In this sense, T4 mentioned that she started using methods that would enable students to use their imaginations, to feel themselves in that problem and to think about how they could find a way out, and in the continuation of the interview, she explained that "I saw how effective it was to use the programs prepared for geometry subjects and I started using this program in my own lessons. My students created different triangles by changing the angles as they want." In addition, T5 stated that she gave more importance to revealing her students' ideas and that she created discussion platforms to ensure this. Therefore, she stated that it is easier to understand which student has what kind of idea. Talking about her approach towards the student, T3 explained her views as follows: "While discussing the subject or any question we solved with the students in my classroom practices, I noticed that I was guiding the students to the truths in my mind." In this sense, T5 stated that she was behaving impatiently and intervened too much with the students. She stated that this situation not only did not allow the student to think, but also prevented the teacher from recognizing the student. Stating that the students could not express their thoughts adequately, T1 explained this situation as follows: "I saw that especially the students had difficulties in using mathematical expressions. This can lead to incomprehension of what the student wants to tell. " Similarly, T4 stated that she cares about students' ideas and even if they give wrong answers, she tries to understand their thinking by listening to them. Whereas T2 stated that he accepted every opinion of the students without questioning whether it was correct or not, and started to question students' ideas to prevent this. Approaching this situation with a different perspective, T1 said, "The fact that teachers give importance to questioning students 'ideas improves students' mathematical understanding. Because the student knows after a while that if I say this answer, the teacher will also ask how I did it and ask why I think so." Actually, T1 mentioned the social norms that are described as implicit rules established in the classroom. On the other hand, T4, who wanted to be sure whether the student understood the solution of any problem or not, mentioned that she included alternative problems in her classroom practices. 
She also stated that she supports students to develop different solution ways in problem solving and gives students time to think. Similarly, T1 stated that she tried to learn how the student thought and expressed her views as follows in the continuation of the interview: "I want students not to stick to a single solution. For this, I give them the opportunity to try different solutions and develop new strategies to control them."

In the interviews, it was seen that the teachers talked about the approaches they noticed and adopted in the video club. These were determined as focusing on the cause instead of the result, learning while teaching, learning to question, and learning discourses that cause misconceptions. These approaches of teachers are grouped under the category of teacher learning. Most of the teachers stated that they noticed some discourses that could cause misconceptions while evaluating the videos. T3 explained her views about this as follows: "I learned that I need to pay more attention to some small points in my information exchange with my students and this small point from the eyes of the students may actually cause misleading, and it caused me to be more careful about this issue" On the other hand, T1 focused on a different reason of misconception by expressing the view that "...the expressions we use are generalized by the students and this causes misconceptions". In addition, T2 stated that she learned to focus on causes, not results, in video club activities, and related this situation to students' mathematical thinking. Her views on this situation are as follows: “...I learned to question the correct and incorrect answers of the students. I learned that I shouldn't just focus on the correct result, questioning the answers of students, and understanding why they think this way." T4 stated that she saw herself as a learner in a situation where the student was trying to understand the solution and she said: "I thought a little to understand the solution way of my student. At that moment, I could not be sure of the student's solution. Then I looked at my lecture notes and compared it with my own solution..."

The views of the teachers reflecting their experiences of watching and analyzing the video lessons of their classes in the video club process are classified under two categories in Table 2. According to teachers, the advantages of watching and analyzing their own lessons are as follows: seeing their communication with students, evaluating their lessons as an observer, self-criticizing, seeing the classes from different angles and paying attention to situations they do not consider.

Table 2 Teachers' Views Reflecting Their Experiences of Analyzing Their Class Videos

\begin{tabular}{lcc}
\hline Categories & Codes & Teachers \\
\hline & Seeing their communication with their students & $\mathrm{T} 1$
\end{tabular}

Seeing their communication with their students T1

Necatibey Eğitim Fakültesi Elektronik Fen ve Matematik Eğitimi Dergisi

Necatibey Faculty of Education, Electronic Journal of Science and Mathematics Education 


\begin{tabular}{lll}
\hline \multirow{4}{*}{ Advantages } & in the classroom & \\
& Self-assessment as an observer & T1, T2, T3, T4, T5 \\
& Self-criticism towards teaching practices & T1, T3, T4, T5 \\
& View classes from different angles & T2 \\
& Ignoring situations that are not considered & T1, T4, T5 \\
\hline Disadvantages & Avoiding being reflective & T2, T3 \\
\hline
\end{tabular}

When Table 2 is examined, all of the teachers stated that their experience of analyzing their video lessons enabled them to evaluate their lessons as observers. Regarding this situation, T1 stated that "I tried to evaluate my lessons as an external observer." T4 evaluated their practices as follows: “...there were situations where I said I was good, what I did, and there were situations when I said that. Like holding the mirror to yourself..." Stating that watching her own video lessons is a different feeling, T5 stated that she was trying to see the missing aspects by observing the teaching practices. In this context, she made a self-criticism of teaching practices by stating that she did not give enough time to the student and behaved very impatiently. Regarding this, T3 expressed her self-criticism towards her practices as follows: "I saw that I sometimes affected the students very much. In fact, I gave them the opportunity to think while discussing a question, I listened to different ideas, but I saw that I was trying to convince them according to the truth in my mind ... " Most of the teachers stated that they started to care about some situations that they did not consider in the classroom thanks to video analysis. For example, T1's explanations about this were as follows: "I saw that some things that I ignored or overlooked in the classroom were important... Although I solved it on the board, I considered it an ordinary solution at that moment. But during the video analysis, I realized that my student made a high-end solution." Expressing that it is very enjoyable to watch her own classroom videos, T2 stated that thanks to video analysis, she looks at the classroom from more than one aspect, not just one aspect. In this direction, T1 said that "While watching the video, I do not only see my own behavior, but also see what each student does, how he thinks, and how he learns..." and she evaluated the classroom by observing it from multiple perspectives. On the other hand, two teachers expressed negative views about their experiences of analyzing by watching their classroom videos. What teachers consider negatively is their avoidance of being reflective of the facts about their classroom practices. Under this perspective, T2 stated her ideas as follows: "Even if we think that we evaluate our own teaching practices as an observer, I do not think it is objective enough because we avoid talking about our own shortcomings..." 
Teachers' views reflecting their experience of analyzing colleagues' class videos in the video club process were classified under two categories and given in Table 3.

Table 3 Teachers' Views Reflecting Their Experience of Analyzing Colleagues' Class Videos

\begin{tabular}{lll}
\hline Categories & \multicolumn{1}{c}{ Codes } & \multicolumn{1}{c}{ Teachers } \\
\hline \multirow{4}{*}{ Outcomes } & Observing and evaluating different teaching practices & $\mathrm{T} 1, \mathrm{~T} 2, \mathrm{~T} 3, \mathrm{~T} 4, \mathrm{~T} 5$ \\
& Making inferences & $\mathrm{T} 2, \mathrm{~T} 3, \mathrm{~T} 4, \mathrm{~T} 5$ \\
& Developing a critical view & $\mathrm{T} 2, \mathrm{~T} 3, \mathrm{~T} 4$ \\
& Paying attention to teacher and student interactions & $\mathrm{T} 4$ \\
& Examining student views on different subjects & $\mathrm{T} 1, \mathrm{~T} 2, \mathrm{~T} 4$ \\
\hline \multirow{3}{*}{ Negativities } & Lack of information about student levels & $\mathrm{T} 2, \mathrm{~T} 4$ \\
& Situations where student expressions are not understood & $\mathrm{T} 1, \mathrm{~T} 2$ \\
& Lack of observation opportunity in the classroom & $\mathrm{T} 2$ \\
& Not recognizing students & $\mathrm{T} 2, \mathrm{~T} 5$ \\
\hline
\end{tabular}

All of the teachers mentioned that their colleagues watching and analyzing classroom videos allow them to observe the practices of different teachers. Regarding this situation, T4 stated her ideas that "It was good for us to watch the classroom videos of the teachers in terms of seeing how the teachers behaved as well as the students and what methods they used." In the rest of the interview, she explained this with an example: "For example, students were very comfortable in a teacher's classroom. While one group of materials was trying to solve the question in their hands, another group was trying to solve it on the board and some were trying to solve it individually on the spot. There was noise, but the teacher was used to it, I guess she didn't care. The important thing was that the students achieved the results themselves... It was a lesson that I liked very much, and while I was watching, I thought if I could do it." T2 compared her practices with those of other teachers and stated her views as follows: “...while allowing me to observe different methods other than my own expression methods, it also enabled me to make comparisons. There were methods I learned while watching and I thought that this method was more appropriate... " Mentioning that video clubs provide the opportunity to observe the classes of their colleagues, T3 said that “... watching videos was beneficial for me. Because I found a truth to add to myself in every detail, I think the results I have drawn from my observations and analyzes are beneficial." Most of the teachers stated that by analyzing the video lessons of their colleagues, they developed a critical view of the teaching practice. For example, T5 stated that she developed a critical view of her practices as follows: "I started to make a logical questioning while watching the practices of different teachers. I 
made comparisons both with my own applications and with others... There were times when I said that he should have used a different approach here" In addition, T4 expressed a different view from other teachers and stated that she paid attention to the interactions between the teacher and the students while watching the videos. She also mentioned that teachers try to understand the students' ideas by observing their practices in different subjects, and explained her views in this direction as follows: "It is really difficult to understand how students think about some subjects. Many find it difficult to express their views. While watching the videos, I tried to understand where and how the students answered. But I realized that in order to understand this better, I had to get to know the student closely." On the other hand, teachers mentioned four situations that made it difficult for their colleagues to analyze the lecture videos. Most of the teachers stated that they had difficulty in analyzing the videos they watched because they did not have enough information about students' pre-learning. For example, regarding this situation, T2 expressed her views as follows: "The biggest problem was that we did not know whether the students' prior knowledge was sufficient or not while analyzing." According to T2, not knowing which student is at what level is one of the negativities they experienced while analyzing the videos. In addition, she stated that the expressions of the students were not fully understood in some videos and that it was difficult for them to make evaluations by watching the video instead of participating in the lessons and making observations.

The views of the teachers reflecting their experiences regarding the discussion meetings held during the video club were examined and presented in Table 4 under two categories. During the interview, the teachers talked about the experiences they improved in the video club discussion meetings, and also expressed their difficulties.

Table 4 Teachers' Views Reflecting Their Experiences on Video Club Discussion

Meetings

\begin{tabular}{lll}
\hline Categories & \multicolumn{1}{c}{ Codes } & Teachers \\
\hline \multirow{5}{*}{ Positive aspects } & Developing different perspectives & T2, T3, T4, T5 \\
& Using time effectively & T4 \\
& Collaborate & T1, T2, T3, T4, T5 \\
& Taking on the role of researcher & T1, T2, T4, T5 \\
& Focus on the student & T1, T2, T3, T4, T5
\end{tabular}




\begin{tabular}{lll}
\hline & Looking through the eyes of a student & T2, T3, T5 \\
& Questioning skill & T2, T4, T5 \\
& Benefiting from teacher experiences & T1, T2, T3, T4, T5 \\
& Mathematics educator participation & T1, T5 \\
\hline \multirow{3}{*}{ Negative aspects } & Difficulty getting together & T1, T2, T3, T4, T5 \\
& Lack of time & T1, T2, T3, T4, T5 \\
& Long meetings & T1, T4 \\
\hline
\end{tabular}

When Table 4 is examined, all of the teachers stated that the positive aspects of the video club discussion meetings are that they work more collaboratively, focus on the student, and benefit from each other's experiences. In addition, the teachers treated the discussion meetings as environments where they gave feedback by evaluating different classroom practices together. T5 stated that she started to focus on certain students instead of the general class in the discussion meetings and made her explanations as follows: "Some students understand very quickly, have no problem in learning, but in some the situation is changing ... Here we tried to pay attention to student ideas, understand them and interpret them together." Regarding this, T4 stated that when she first watched the video lectures, more teachers paid attention to classroom management, but they started to talk more about student responses in meetings. T3 made the explanation as "...it was providing a separate observation opportunity for each of us and shaping our perspectives. So now we could analyze the events through the eyes of the student." Taking a different point from other teachers, T2 mentioned that she sees herself as a researcher by researching student ideas, questioning and discovering new methods through club meetings. Most of the teachers considered the video club meetings as an environment where they exchange ideas and contribute to developing different perspectives. T5 explained her ideas in this direction as follows: "We shared our views in the discussion meetings to understand how the student thinks. We started to look at the same event from different angles by benefiting from each other's experiences..." Regarding this, T1 stated that they have opportunities to see different teachers' perspectives. Evaluating the participation of a mathematics educator in the video club discussion meetings as a positive aspect of the meetings, T1 expressed her views about this situation as follows: "...he mentioned some methods that I had not used before. We 
talked about asking questions with missing data. Will the student realize that what is given in the question is missing or will he try to solve the question with the given? I started to include such questions to see this. " T5 stated that the mathematics educator asked detailed questions about the videos they watched and stated that the situations they did not pay attention to were actually important clues. On the other hand, all the teachers mentioned that they had difficulties in getting together in video club discussion meetings and the lack of time affected this situation. For example, $\mathrm{T} 4$ stated that it was very difficult for them to come together in meetings, while T3 stated that they had difficulties due to lack of time. Thinking that the school administration should provide support for studies that support such teacher professional development, T2 mentioned that they had problems in getting together due to the full curriculum. In addition, T1 and T4 evaluated the long duration of discussion meetings as a negative situation and talked about the exhausting routine work of the school.

After the teachers' views reflecting their experiences about the process were received, they were asked to offer alternative solutions to eliminate the negative aspects of the process. For this purpose, the following question was asked to the teachers during the interview: "What are your suggestions for designing this process more effectively as a result of your video club experiences? The categories and codes created by analyzing the answers given by the teachers are shown in Table 5.

Table 5 Teachers' Views About An Effective Video Club Design

\begin{tabular}{lll}
\hline Categories & \multicolumn{1}{c}{ Codes } & \multicolumn{1}{c}{ Teachers } \\
\hline \multirow{2}{*}{$\begin{array}{l}\text { School-researcher } \\
\text { collaboration }\end{array}$} & Meeting place and time can be set & T1, T2, T3, T4, T5 \\
& $\begin{array}{l}\text { Course program can be arranged } \\
\text { Seacher professional development can be }\end{array}$ & $\mathrm{T} 1, \mathrm{~T} 2, \mathrm{~T} 3, \mathrm{~T} 4, \mathrm{~T}$, T2, T4 \\
& Concept teaching can be done & $\mathrm{T} 2$ \\
& Teachers' demands and needs can be determined & $\mathrm{T} 1, \mathrm{~T} 2, \mathrm{~T} 5$ \\
& There may be different grade levels & $\mathrm{T} 4$ \\
Teacher-researcher & It can be a grade level & $\mathrm{T} 2, \mathrm{~T} 5$ \\
collaboration & $\begin{array}{l}\text { Alternative measurement methods can be } \\
\text { examined }\end{array}$ & $\mathrm{T} 2$ \\
\hline \multirow{2}{*}{$\begin{array}{l}\text { Inter-institutional } \\
\text { collaboration }\end{array}$} & Lesson plans can be prepared & $\mathrm{T} 1$ \\
\hline & Sustainable & $\mathrm{T} 3$ \\
& It can be used for teacher education & $\mathrm{T} 1, \mathrm{~T} 2, \mathrm{~T} 3, \mathrm{~T} 5$ \\
\hline
\end{tabular}


When Table 5 is examined, the suggestions of the teachers for an effective video club design are grouped under three categories: school-researcher collaboration, teacher-researcher collaboration and inter-institutional collaboration. Most of the teachers mentioned setting the meeting place and time as a priority in designing a more efficient video club process. In this direction, T1 emphasized that there should be school support in order to adjust the time better. $\mathrm{T} 3$, on the other hand, stated that the school administration and the researcher should make arrangements together before the study starts in order to avoid time and meeting difficulties. In addition, teachers stated that the full curriculum was a problem in arranging the meeting times. Regarding this situation, T5 explained his views as follows: " ...we tried to arrange the time we were available in our lesson programs. However, our empty lessons did not match. In order to avoid this problem, school administrators can afford at least one hour in the curriculum of the teachers participating in the study." Three of the teachers mentioned that the school administration should implement practices that encourage teachers for professional development. For example, T2 explained her views as follows: "Schools should support their teachers for these activities. School administrators should take time for group teachers to work together. It can be during the seminar periods or it can be arranged one hour a week..." In line with these suggestions, it can be said that the teachers agree on the collaboration between the researcher and the school. On the other hand, the teachers claimed that it would be more effective to design club activities in line with their demands and needs. In this sense, the teachers stated that it is important to choose the subject together. For example, T4 explained her views as follows: "Different topics can be told. We can decide together which topics will be. We can examine how students think about different grade levels." On the other hand, T2 suggested that the same subjects at a grade level should be examined by teachers and the deficiencies should be determined. Therefore, while T4 stated that subjects at different class level should be examined, T2 argued that the same subjects should be examined at one grade level. However, both teachers agree that subjects should be chosen together. In addition, T2 mentioned that video clubs are designed for concept teaching. According to T2, concepts can be handled instead of the subject. Because concepts need to be learned in order to understand the subject, and it is more important to reveal students' thoughts about concepts first. In addition she suggested that quizzes could be used to determine how well the concepts were understood by students and that alternative assessment methods should be examined together. T1 stated that it would be effective to prepare lesson plans together with colleagues by determining the subjects that the student had learning difficulties. Teachers' suggestions for the sustainability of 
video clubs, generalization and use in teacher education are classified under the category of institutional collaboration. Most of the teachers stated that their continuity is necessary for professional development activities to be effective. In this sense, Ö5 emphasized that video clubs should not be limited to a certain period of time and that they should have continuity. T3, on the other hand, suggested that video clubs should be generalized and expressed her views as follows: "This practice can be a generalized activity programmed in all educational institutions. It can be used as an effective practice in both teacher training and teacher development." Similarly, T2 stated that working in cooperation increased their motivation and stated that club practices should be done continuously in line with the determined needs.

\section{Conclusion and Discussion}

This study was carried out to reflect the experiences of middle school mathematics teachers who participated in the video club process. In the study, firstly, the contributions of video clubs to the professional development of teachers were examined. From the views expressed by the participant teachers on their professional development, it can be said that video clubs support teachers' noticing, student recognition, sensitive teaching practices and teacher's learning. Many studies on the subject show that video clubs improve teacher skills for noticing and interpreting student thinking (Jacobs, Lamb \& Philipp, 2010; Sherin \& Han 2004; Sherin \& van Es, 2005; Sherin \& van Es, 2009; van es \& Sherin, 2008). As it can be understood from here, the findings obtained from the views of the teachers support the findings of this research conducted on a subject basis. It was seen that the participating teachers made the most detailed explanations about teaching practices during the interview. It is understood from the views of the teachers that they developed sensitive teaching practices by adopting a student-oriented approach. A similar result can be found in the studies of van Es and Sherin (2010). In their study found that there were three changes in the classroom practices of mathematics teachers participating in the video club: "making space for student thinking", "probing student thinking" and "learning while teaching". In this study, it is understood from the views of the teachers that they try to reveal the ideas of the students by caring, and they develop an interrogative approach to learn where and how the students think. This situation can be considered as a result of teachers trying to get to know the student better by focusing on student thinking in video club meetings. On the other hand, teachers 'views on the contribution of video clubs to professional development are that they support teachers' learning. It was observed that especially under this category, teachers expressed their views that they learned to notice and question more. This 
finding parallels the research results (Luna \& Sherin, 2017; van Es \& Sherin, 2008) showing that video clubs are an efficient process used to reveal teachers' analytical thoughts.

When the views of the teachers in video clubs about their experiences of analyzing their classroom videos are examined, it is seen that they agree especially on self-evaluation and selfcriticism. According to Zhang et al. (2011), teachers' evaluations by watching their own videos are effective in seeing their classes from different angles. In addition, the research of Seidel et al. (2011) shows that teachers' watching and analyzing their own lesson videos provides them with a more effective experience. On the other hand, it is a negative situation that teachers have the possibility to avoid being reflective on their own lessons. This situation prevents teachers from making objective evaluation of their own practices. However, the purpose of teachers in analyzing their own videos is to develop alternative solution strategies by establishing relationships between student thinking and their classroom practices.

Participating teachers think that analyzing the videos of their colleagues provides the opportunity to observe and compare different teaching practices. Similarly, Zhang et al. (2011) found in their study that teachers made comparisons with their own teaching by watching different lesson videos and changed their teaching by assimilating other techniques. Most teachers find that analyzing their colleagues' classroom videos helps them develop a critical stance. In contrast, the studies of Seidel et al. (2011) show that teachers are more involved in discussions and critical discourse about the lesson videos of their colleagues whom they do not know. Although the teachers mentioned the positive aspects of analyzing the class videos of their colleagues, they did not neglect to indicate the difficulties they experienced. However, what is remarkable is that the teachers did not raise these difficulties for their own video analysis. This may be due to the feeling that the negativities they identified in the video are not valid for their lesson videos (Beisiegel et al., 2018; Kleinknecht \& Schneider, 2013).

When the views of the teachers participating in the video club regarding the discussion meetings are examined, they think that it contributes to the experiences of working together, benefiting from each other's experiences and focusing on student thinking. In addition, most of the teachers stated that thanks to the meetings, they formed different perspectives, started to look at students' eyes and gained questioning skills. According to Sherin (2003), video clubs include both features of an effective professional development in terms of providing teachers with opportunities to work together and being connected with real classroom practices. In this direction, Wallin and Amador (2019) argue that video clubs positively affect teachers' collaboration. Therefore, the findings obtained are in parallel with the results of the 
aforementioned research. In this sense, video club meetings enable teachers to work in collaboration. It provides an opportunity for itself and its colleagues to evaluate teaching practices from different perspectives. Teachers can learn more about student thinking as a result of videos and interactions with each other in club meetings (Borko et al., 2008). Thus, teachers can analyze students' eyes to understand and interpret student thinking. In addition, participating teachers stated that video club discussion meetings have negative aspects. It is understood that the negative views expressed by the teachers are mostly about gathering and lack of time. As a matter of fact, these mentioned difficulties are not only for the video club but also for the professional development processes carried out with teachers (for example, lesson study model).

Teachers' views on an effective video club design are quite extensive. Teachers' views on this situation are in the direction of researchers working in cooperation with teachers and schools. All of the teachers think that there should be school support to participate in professional development practices. In this sense, they recommend that the researcher and the school act together to determine the meeting place and time and to organize the course schedules. On the other hand, teachers think that video club activities should be designed in line with the demands and needs of teachers in order to be more effective. In this direction, there are also studies showing that video clubs have a flexible structure that can be adapted to the needs and objectives of teachers and teacher educators (Barnhart \& van Es, 2020; Borko et al., 2011). In addition, teachers made suggestions for the sustainability of video club practices in schools and expressed their views on the generalization of these practices and their use in teacher education. These views of the teachers can be considered as an indicator that the video club model can be applied in schools.

\section{Implications}

The findings obtained from the study support the acceptance of video clubs as an effective professional development model. Considering that teachers can make the most accurate evaluations for video clubs, it is thought that this study will contribute to the design of video clubs. Although the views of the teachers reflect the positive features of the video club process, the negative aspects should also be taken into account. From this point of view, alternative solution suggestions made by teachers regarding the negative aspects of the process can be produced. As the teachers stated, support of the school administration can be provided for meeting and lack of time. Thus, conducting video club activities in cooperation with the school 
and the researcher can increase teachers' motivation to work. In addition, in line with the suggestions of the teachers, the demands and needs can be determined in cooperation with the teachers before the video club applications are designed. This situation may be effective in teaching the concepts that students have learning difficulties as well as be useful for teachers to develop different practices.

\section{References}

Akerlind, S. G. (2002). Principles and practice in phenomenographic research. Proceedings of the International Symposium on Current Issues in Phenomenography. Canberra, Australia.

Amador, J. M., Keehr, J., Wallin, A. \& Chilton, C. (2020). Video complexity: Describing videos used for teacher learning. EURASIA Journal of Mathematics, Science and Technology Education, 16(4). https://doi.org/10.29333/ejmste/113288

Barnhart, T. \& van Es, E. A. (2015). Studying teacher noticing: Examining the relationship among pre-service science teachers' ability to attend, analyze and respond to student thinking. Teaching and Teacher Education, 45, 83-93.

Barnhart, T. \& van Es, E. A. (2020). Developing a critical discourse about teaching and learning: The case of a secondary science video club. Journal of Science Teacher Education. https://doi.org/10.1080/1046560X.2020.1725724

Beisiegel, M., Mitchell, R. \& Hill, H. C. (2018). The design of video-based professional development: An exploratory experiment intended to identify effective features. Journal of Teacher Education, 69(1), 69-89. https://doi.org/10.1177/0022487117705096

Borko, H., Jacobs, J., Eiteljorg, E. \& Pittman, M. E. (2008). Video as a tool for fostering productive discussions in mathematics professional development. Teaching and Teacher Education, 24(2), 417-436.

Borko, H., Koellner, K. \& Jacobs, J. (2014). Examining novice teacher leaders' facilitation of mathematics professional development. The Journal of Mathematical Behavior, 33, 149-167.

Borko, H., Koellner, K., Jacobs, J. \& Seago, N. (2011). Using video representations of teaching in practice-based professional development programs. ZDM, 43(1), 175-187.

Brophy, J. (2004). Using video in teacher education. San Diego, CA: Elsevier, Inc. 
Christ, T., Arya, P. \& Chiu, M. M. (2017). Video use in teacher education: An international survey of practices. Teaching and Teacher Education, 63, 22-35.

Coles, A. (2019). Facilitating the use of video with teachers of mathematics: learning from staying with the detail. International Journal of STEM Education, 6(1), 2-13.

Gaudin, C. \& Chaliès, S. (2015). Video viewing in teacher education and professional development: A literature review. Educational Research Review, 16, 41-67.

Goldsmith, L. T. \& Seago, N. (2011). Using classroom artifacts to focus noticing. In M. G. Sherin, V. R. Jacobs, \& R. A. Philipp (Eds.), Mathematics teacher noticing: Seeing through teachers' eyes (pp. 169-187). New York, NY: Routledge.

Guskey, T.R. (2002). Professional development and teacher change. Teachers and Teaching: Theory and Practice, 8, 381-391.

Jacobs, V. R., Lamb, L. L. C. \& Philipp, R. A. (2010). Professional noticing of children's mathematical thinking. Journal for Research in Mathematics Education, 41(2), 169202.

Jilk, L. (2016). Supporting teacher noticing of students' mathematical strengths. Mathematics Teacher Educator, 4(2), 188-199. https://doi.org/10.5951/mathteaceduc.4.2.0188

Luna, M. J. \& Sherin, M. G. (2017). Using a video club design to promote teacher attention to students' ideas in science. Teaching and Teacher Education, 66(1), 282-294. https://doi.org/10.1016/j.tate.2017.04.019

Marton, F. (1986). Phenomenography: A research approach to investigating different understanding of reality. Journal of Thought, 21(3), 28-49.

Ministry of National Education [MEB]. (2017). General qualifications of the teaching profession. General Directorate of Teacher Training and Development, Ankara.

Özdemir-Baki, G. \& Kılıçoğlu, E. (2020). Examination of teachers' classroom practices through a video club process in terms of students' mathematical thinking. Turkish Journal of Computer and Mathematics Education. https://doi.org/10.16949/turkbilmat.704596

Santagata, R. \& Yeh, C. (2013). Learning to teach mathematics and to analyze teaching effectiveness: Evidence from a video- and practice-based approach. Journal of Mathematics Teacher Education, 17(6), 491-514. 
Seago, N. (2004). Using video as an object of inquiry for mathematics teaching and learning. In J. Brophy (Ed.), Using video in teacher education (pp. 259-286). Oxford, UK: Elsevier.

Seidel, T., Stürmer, K., Blomberg, G., Kobarg, M. \& Schwindt, K. (2011). Teacher learning from analysis of videotaped classroom situations: Does it make a difference whether teachers observe their own teaching or that of others? Teaching and Teacher Education, 27, 259-267.

Sherin, M. G. (2004). New perspectives on the role of video in teacher education. J. Brophy (Ed.), Using video in teacher education (pp. 1-27). San Diego, CA: Elsevier.

Sherin, M. G. \& Han, S. Y. (2004). Teacher learning in the context of a video club. Teaching and Teacher Education, 20(2), 163-183.

Sherin, M. G. \& van Es, E. (2005). Using video to support teachers' ability to notice classroom interactions. Journal of Technology and Teacher Education, 13(3), 475-491.

Sherin, M. G. \& van Es, E. A. (2009). Effects of video club participation on teachers' professional vision. Journal of Teacher Education, 60(1), 20-37.

Star, J. R. \& Strickland, S. K. (2008). Learning to observe: Using video to improve preservice mathematics teachers' ability to notice. Journal of Mathematics Teacher Education, 11(2), 107-125.

Stürmer, K., Könings, K. D. \& Seidel, T. (2013). Declarative knowledge and professional vision in teacher education: Effect of courses in teaching and learning. British Journal of Educational Psychology, 83(3), 467-83.

Sun, J. \& van Es, E. A. (2015). An exploratory study of the influence that analyzing teaching has on pre-service teachers' classroom practice. Journal of Teacher Education, 66(3), 201-214.

Tekkumru-Kisa, M. \& Stein, M. K. (2017). A framework for planning and facilitating videobased professional development. International Journal of STEM Education, 4(28).

Trigwell, K. (2006). Phenomenography: An approach to research into geography education. Journal of Geography in Higher Education, 30(2), 367-372.

Van Es, E. A. (2011). A framework for learning to notice student thinking. M. G. Sherin, V. R. Jacobs, \& R. A. Philipp (Eds.), Mathematics teacher noticing: Seeing through teachers' eyes (pp. 134-151). New York: Routledge. 
Van Es, E. A., Cashen, T., Barnhart, T. \& Auger, A. (2017). Learning to notice mathematics instruction: Using video to develop preservice teachers' vision of ambitious pedagogy. Cognition and Instruction, 35(3), 165-187.

Van Es, E. A. \& Sherin, M. G. (2008). Mathematics teachers" "learning to notice" in the context of a video club. Teaching and Teacher Education, 24, 244-276.

Van Es, E. A. \& Sherin, M. G. (2010). The influence of video Clubs on teachers' thinking and practices. Journal of Mathematics Teacher Education, 13(2), 155-176.

Wallin, A. J. \& Amador, J. M. (2019). Supporting secondary rural teachers' development of noticing and pedagogical design capacity through video clubs. Journal of Mathematics Teacher Education, 18(6), 523-550.

Yıldırım, A. \& Şimşek, H. (2016). Qualitative research methods in the social sciences (10th edition). Ankara: Seçkin Yayıncılık.

Zhang, M., Lundeberg, M., Koehler, M. J. \& Eberhardt, J. (2011). Understanding affordances and challenges of three types of video for teacher professional development. Teaching and Teacher Education, 27(2), 454-462. 